UNIVERSIDADE DE BRASÍLIA

FACULDADE UNB PLANALTINA

\title{
Síntese, Caracterização e Aplicação de Nanoadsorventes Magnéticos Visando à Remoção de $\mathrm{Cr}(\mathrm{VI})$ de Águas Residuais
}

PLANALTINA 2016 


\section{Síntese, Caracterização e Aplicação de Nanoadsorventes Magnéticos Visando à Remoção de $\operatorname{Cr}(\mathrm{VI})$ de Águas Residuais}

Dissertação apresentada à Faculdade UnB Planaltina da Universidade de Brasília, como requisito parcial para obtenção do grau de Mestre em Ciência de Materiais.

Orientador: Prof. Dr. Alex Fabiano C. Campos.

Brasília

2016 
Ficha catalográfica elaborada automaticamente, com os dados fornecidos pelo(a) autor(a)

As

Augusta Lisboa de Oliveira, Helena

Síntese, caracterização e aplicação de

nanoadsorventes magnéticos visando à remoção de $\mathrm{Cr}(\mathrm{VI})$ de águas residuais / Helena Augusta Lisboa de Oliveira; orientador Alex Fabiano Cortez Campos. -Brasilia, 2016.

$71 \mathrm{p}$.

Dissertação (Mestrado - Mestrado em Ciência de Materiais) -- Universidade de Brasilia, 2016.

1. O Cromo e o Meio Ambiente. 2. Síntese dos Nanoadsorventes. 3. Influência de Variáveis na Remoção de $\operatorname{Cr}(\mathrm{VI})$. 4. Recuperação e Reutilização de Nanoadsorventes Magnéticos. I. Fabiano Cortez Campos, Alex, orient. II. Título. 
Síntese, Caracterização e Aplicação de Nanoadsorventes Magnéticos Visando à Remoção de $\mathrm{Cr}(\mathrm{VI})$ de Águas Residuais

Dissertação apresentada à Faculdade UnB Planaltina da Universidade de Brasília, como requisito parcial para obtenção do grau de Mestre em Ciência de Materiais.

Aprovada em de de

COMISSÃO EXAMINADORA

Prof. Dr. Alex Fabiano C. Campos

Faculdade UnB - Planaltina

Orientador

Profa. Dra. Ariuska Karla Barbosa Amorim

Faculdade de Tecnologia - UnB

Membro

Prof. Dr. Marcelo Henrique Sousa

Faculdade UnB - Ceilândia

Membro

Brasília, 19 de fevereiro de 2016. 
"É propriamente não valer nada não ser útil a ninguém."

(René Descartes) 


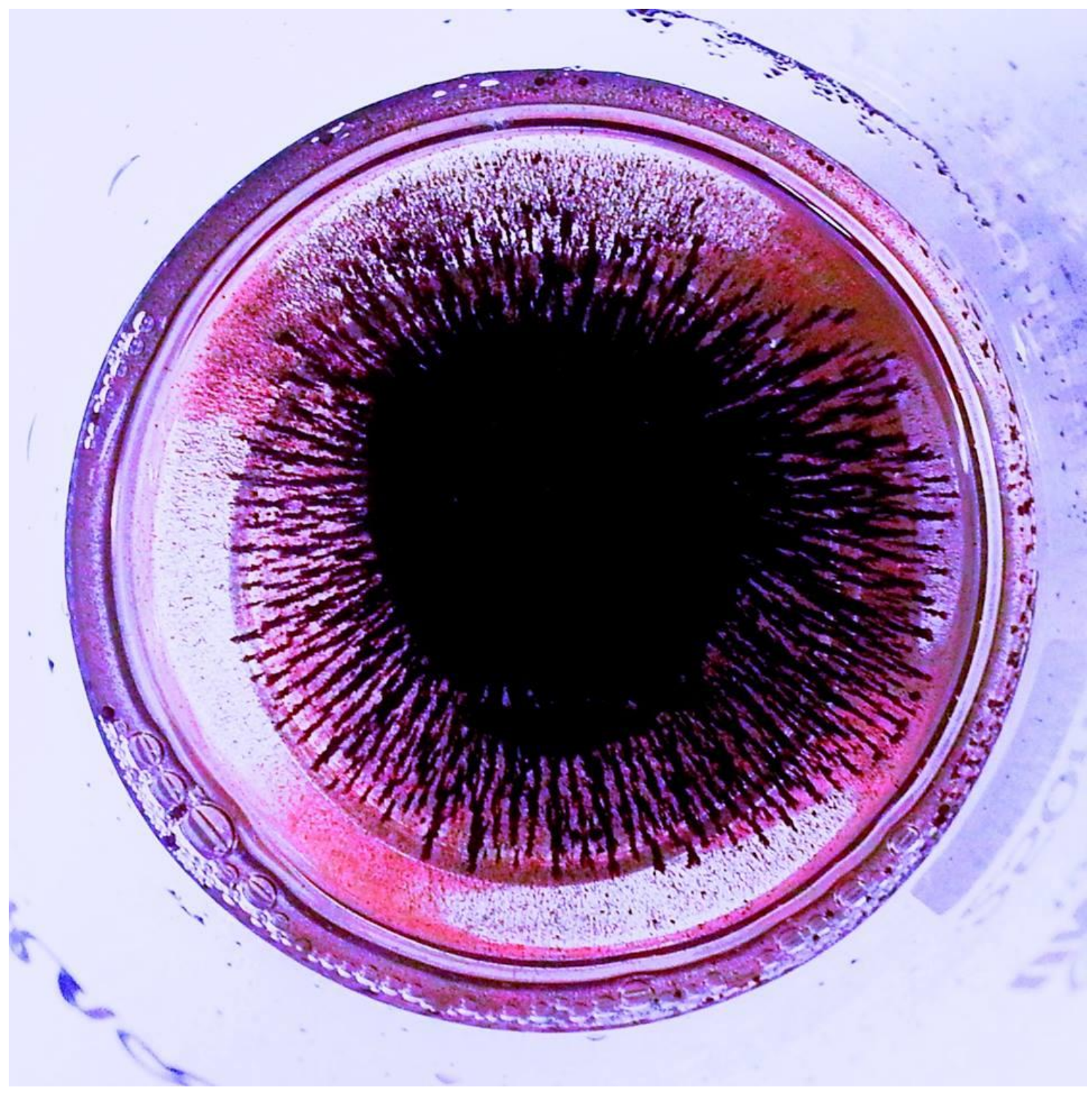

Nanopartículas core-shell seguindo as linhas de campo.

Imagem vencedora do concurso Superfícies em Imagem, promovido pelo Instituto Nacional de Engenharia de Superfícies com apoio do CNPq em 2015.

Fotografia de Helena Augusta Lisboa de Oliveira com edições no brilho e contraste e nas cores, com desvio para o magenta. 


\section{AGRADECIMENTOS}

Este trabalho não seria possível sem o ilustre professor Alex, que me orientou com boa vontade, respeito e confiança.

Aos professores Ariuska e Marcelo por terem aceitado participar da banca e terem corrigido esse trabalho com tanto respeito e atenção.

Ao Estêvão por se dispor a me atender nas situações de dúvidas e ter sido um admirável companheiro.

Aos meus queridos pais Regina e Beto pela oportunidade que me deram e dão de vida, pela educação e amor louváveis.

Às irmãs Paula, pelo auxílio na decisão de cursar Ciências Naturais, e Aniger.

À Daisy, ao Sam e ao Vitinho pela amizade e auxílio nos experimentos.

À Vanessa pela amizade e companhia, e a todo o pessoal do laboratório 3NANO.

Aos professores Paulo, Renata, Mariana e Alexandre por constribuirem de forma especial na minha formação.

Ao Aristides e ao Jorivê pelo epenho e zelo no trabalho.

Ao Webert e ao Franciscarlos por fornecerem as amostras utilizadas neste trabalho.

Aos defensores do povo brasileiro, por considerarem importante a Educação e, aos poucos, proporcionarem maiores oportunidades de estudo, uma das quais pude contemplar pela criação da Faculdade UnB Planaltina.

$E$, finalmente, aos órgãos que fomentaram este trabalho: FAP-DF, FINATEC, CAPES e CNPq. 


\section{RESUMO}

O homem interage e afeta o meio ambiente todos os dias. A poluição gerada por ele prejudica não somente sua saúde, mas toda a fauna e flora. Os efluentes industriais são a principal fonte de poluição de ambientes aquáticos por metais pesados. A recuperação do $\mathrm{Cr}(\mathrm{VI})$, metal pesado altamente tóxico presente nos efluentes, é uma opção atrativa por razões econômicas e ambientais. O presente trabalho teve como objetivo o desenvolvimento de uma nova nanotecnologia para remediação ambiental em que foram elaborados, caracterizados e aplicados nanoadsorventes magnéticos baseados em nanopartículas core-shell do tipo $\mathrm{CoFe}_{2} \mathrm{O}_{4} @ \gamma-\mathrm{Fe}_{2} \mathrm{O}_{3}$ para remoção do $\mathrm{Cr}(\mathrm{VI})$ de meios aquosos. Os nanoadsorventes foram sintetizados pelo método de coprecipitação, que tem baixo custo energético e permite a preparação de nanopartículas de baixa polidispersão em tamanho e controle de tamanho médio, que no caso resultou em nanoadsorventes de 7,20 nm e 13,80 nm de diâmetro (rotulados como FPCo1 e WCo1, respectivamente). A remoção do $\mathrm{Cr}(\mathrm{VI})$ do meio aquoso se faz pela adsorção, método avançado de alta eficiência, em especial por se tratar de adsorventes em escala nanométrica, neste caso, possuindo grande área superficial, seguido de separação química magneticamente assistida, método rápido e também de alta eficiência. Nesse contexto, foram realizados ensaios para avaliar parâmetros importantes no processo de adsorção como $\mathrm{pH}$, tempo de contato entre o adsorvente e a solução contaminada, concentração inicial de poluente, taxa de agitação da solução em contato com os nanoadsorventes e tamanho médio do nanoadsorvente. As condições ótimas para a adsorção mais eficiente com $5 \mathrm{~g} / \mathrm{L}$ de nanoadsorvente foram: $\mathrm{pH}=2,5$, tempo de contato mínimo de 5 minutos, agitação de 400 RPM, e nanoadsorvente de menor tamanho, FPCo1. A capacidade de adsorção estimada foi de $11,33 \mathrm{mg} / \mathrm{g}$ para o WCo1 e $15,34 \mathrm{mg} / \mathrm{g}$ para o FPCo1. Ao final, os nanoadsorventes usados passaram por ciclos de dessorção visando à recuperação, que foi de cerca de $63,35 \%$ para 0 WCo1 e 52,34\% para o FPC 1 . O Cr(VI) removido pode, posteriormente, ser transformado em matéria prima com valor agregado, de forma econômica e ambientalmente vantajosa, sem que haja a geração de resíduo. 


\section{PALAVRAS-CHAVE: Nanoadsorventes magnéticos, remoção de cromo, águas residuais.}

\section{ABSTRACT}

Everyday the man interacts and affects the environment. The pollution generated impair not only the human health, but also all the fauna and flora. The industrial effluents are the major source of water pollution by heavy metals. The recovery of $\mathrm{Cr}(\mathrm{VI})$, a highly toxic heavy metal present in wastewater, is an attractive option for economic and environmental reasons. This study aimed to develop a new nanotechnology to environmental remediation, in which the magnetic nanosorbents were elaborated, characterized and applied based on core-shell nanoparticles of the type $\mathrm{CoFe}_{2} \mathrm{O}_{4} @ \gamma-\mathrm{Fe}_{2} \mathrm{O}_{3}$ for $\mathrm{Cr}(\mathrm{VI})$ removal on aquatic environment. The nanosorbents were synthesized by the coprecipitation hydrothermal method, that has low energy cost and allows the preparation of low size dispersion nanoparticles and average size control, resulting in 7,20 nm and 13,80 nm nanosorbents diameter (labeled as FPCo1 and WCo1, respectively). The removal of $\operatorname{Cr}(\mathrm{VI})$ from aqueous solution was made by adsorption, an advanced method with higher efficiency, especially because the adsorbents are in nanoscale, thus, resulting in a large superficial area, followed by magnetically assisted chemical separation, which is a modern and fast method and also highly efficient. In this context, assays were performed to evaluate important parameters in the adsorption process such as $\mathrm{pH}$, contact time between the adsorbent and the contaminated solution, initial pollutant concentration, speed of stirring and medium size nanosorbent. The optimum conditions for the most efficient absorption using $5 \mathrm{~g} / \mathrm{L}$ of nanosorbent were: $\mathrm{pH}=2,5$, minimum contact time of 5 minutes, stirring of $400 \mathrm{RPM}$, and nanosorbent smaller, FPCo1. The estimated adsorption capacity was 11.33 $\mathrm{mg} / \mathrm{g}$ for the WCo1 and $15.34 \mathrm{mg} / \mathrm{g}$ for the FPCo1. At the end, the used nanosorbents undergone desorption cycles for retrieval, which was of $63.35 \%$ for WCo1 and $52.34 \%$ for FPCo1. The removed $\mathrm{Cr}(\mathrm{VI})$ can be later refurbished 
in raw material with added value, in an economical and environmentally friendly manner without waste production.

KEYWORDS: magnetic nanosorbens, $\mathrm{Cr}(\mathrm{VI})$ removal, wastewater. 


\section{LISTA DE FIGURAS}

Figura 1: Estrutura da nanopartícula. De acordo com o modelo core-shell: um núcleo de ferrita de cobalto $\left(\mathrm{CoFe}_{2} \mathrm{O}_{4}\right)$ recoberto por uma superfície de maguemita $\left(\gamma-\mathrm{Fe}_{2} \mathrm{O}_{3}\right)^{23}$ 28

Figura 2: Relação entre a área e o volume de um objeto de forma regular. Para um mesmo volume de esferas de um mesmo tamanho, maior será a soma das áreas superficiais das esferas quanto menores elas forem ${ }^{24}$ 28

Figura 3: Fotos de momentos da síntese do nanoadsorvente WCo1. (1) solução de $\mathrm{NaOH} 2 \mathrm{~mol} / \mathrm{L}$ em fervura e agitação; (2) soluções de $\mathrm{FeCl} 2$ e de $\mathrm{Co}\left(\mathrm{NO}_{3}\right)_{3}$ que serão adicionadas ao $\mathrm{NaOH}$; (3) Soluções logo após a adição. 30

Figura 4: Fotos de etapas da síntese dos nanoadsorventes. (1) sistema com nanopartículas recém formadas em repouso; (2) tratamento superficial das nanopartículas com $\mathrm{Fe}(\mathrm{NO} 3)_{3}$; (3) lavagem dos nanoadsorventes; ferrofluido formado no processo de síntese dos nanoadsorventes; (5) precipitado seco; (6) nanoadsorventes prontos

Figura 5: Lei de Bragg e caminhos dos raios difratados através dos planos cristalográficos de uma amostra ${ }^{25}$ 33

Figura 6: Difratometria de raios X das amostra de nanoadsorventes FPCo1 (a) e WCo1 (b).

Figura 7: Imagem obtida por Microscopia Eletrônica de Transmissão (TEM) dos nanoadsorventes FPCo1 (a primeira) e WCo1 (a segunda). 36 Figura 8: Histograma de tamanhos das amostras dos nanoadsorventes FPCo1 (a) e WCo1 (b) 36

Figura 9: Magnetização dos nanoadsorventes WCo1 e FPCo1 38

Figura 10: Comparação entre a separação química dos nanoadsorventes FPCo1 e WCo1 no decorrer do tempo sem auxílio do ímã (a) e com o auxílio do ímã (b).

Figura 11: Fotos de etapas dos testes de adsorção. (1) bateria de amostras com concentração inicial e pH estabelecidos; (2) adição de nanoadsorventes à amostra; (3) recipientes vedados com os nanoadsorventes; (4) amostras sendo agitadas; (5) sobrenadante sendo retirado e (6) nanoadsorventes usados devidamente separados do sobrenadante. 
Figura 12: Sala do Espectrômetro de Absorção Atômica (AAS) no laboratório 3Nano/UnB.

Figura 13: Resultado de FTIR para os dois nanoadsorventes estudados com e sem $\mathrm{Cr}(\mathrm{VI})$ adsorvido. 44

Figura 14: Porcentagem de remoção de $\mathrm{Cr}(\mathrm{VI})$ em função do tempo. 46

Figura 15: Ajuste com o modelo de cinética de Pseudo Segunda-Ordem. ...... 50 Figura 16: Ajuste dos resultados com as Isotermas de Langmuir (a) e Freundlich (b). 54

Figura 17: Diagrama das especiações do $\mathrm{Cr}(\mathrm{VI})$ em diferentes concentrações e $\mathrm{pHs}^{48}$. 55

Figura 18: Diagrama representativo das espécies ocorrentes de $\mathrm{Cr}(\mathrm{VI})$ (em vermelho) e da superfície do nanoadsorvente (em preto) em meios aquosos por $\mathrm{pH}$ 56

Figura 19: Dependência da remoção de $\mathrm{Cr}(\mathrm{VI})$ pelo pH da solução. 57 Figura 20: Esquema de possível interação entre a superfície do nanoadsorvente e o meio carregado positivamente (a) e negativamente (b) ${ }^{22} .58$ Figura 21: Influência da taxa de agitação na remoção de $\mathrm{Cr}(\mathrm{VI})$. 59

Figura 22: Dessorção do $\mathrm{Cr}(\mathrm{VI})$. A solução que inicialmente estava transparente, após a agitação, ficou escurecida. Isso ocorreu em cada ciclo. A cor resultante é proveniente do $\mathrm{Cr}(\mathrm{VI})$ dessorvido dos nanoadsorventes. 63 Figura 23: Recuperação relativa dos nanoadsorventes a cada ciclo de dessorção 64

Figura 24: Comparação entre a porcentagem de remoção de $\mathrm{Cr}(\mathrm{VI})$ de cada nanoadsorvente antes e depois da recuperação. 65 


\section{LISTA DE TABELAS}

Tabela 1: Valores Máximos admissíveis para o cromo em efluentes............... 23 Tabela 2: Resumo dos resultados de caracterização morfológica dos

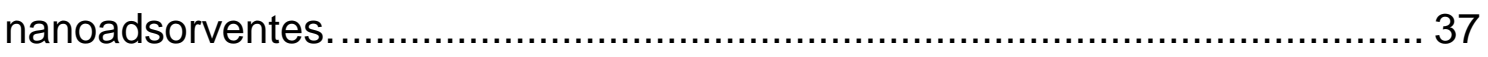

Tabela 3: Resumo dos resultados de caracterização morfológica dos nanoadsorventes.

Tabela 4: Condições fixadas para os oito testes para avaliar a influência do tempo de contado. Cada teste contou com 6 amostras variando o tempo de contato. 45

Tabela 5: Porcentagem e quantidade máxima de remoção de $\mathrm{Cr}(\mathrm{VI})$ em função da concentração inicial de poluente e do $\mathrm{pH}$ para os nanoadsorventes investigados.

Tabela 6: Valores de Coeficiente de Correlação $\left(R^{2}\right)$ obtidos pelo ajuste dos resultados cinéticos com os modelos de Pseudo Primeira-Ordem e Pseudo Segunda-Ordem para cada teste.

Tabela 7: Parâmetros do modelo de pseudo segunda-ordem para cada teste. 50 Tabela 8: Parâmetros obtidos de cada Isoterma. 53

Tabela 9: Parâmetros termodinâmicos do processo de adsorção estimados sob temperatura ambiente. 61 


\section{LISTA DE SÍMBOLOS}

$a_{e}$ : atividade do $\mathrm{Cr}(\mathrm{VI})$ em solução no equilíbrio

$a_{s}$ : atividade do $\operatorname{Cr}(\mathrm{VI})$ adsorvido

$\mathrm{C}_{\mathrm{e}}$ : concentração do soluto em equilíbrio

$C_{\text {s: }}$ concentração do $\mathrm{Cr}(\mathrm{VI})$ adsorvido no nanoadsorvente

d: distância interplanar

D: diâmetro médio das partículas

$\mathrm{H}$ : módulo do campo magnético aplicado

$\mathrm{K}$ : constante que depende da forma das partículas

$K_{0}$ : constante termodinâmica do equilíbrio de adsorção

$\mathrm{k}_{1}$ : contante da reação de Pseudo Primeira-Ordem

$\mathrm{k}_{2}$ : constante da reação de Pseudo Segunda-Ordem

$\mathrm{k}_{\mathrm{a}}$ : constante de adsorção

$\mathrm{k}_{\mathrm{d}}$ : constante de dessorção

$\mathrm{K}_{\mathrm{F}}$ : constante de Freundlich

$\mathrm{K}_{\mathrm{L}}$ : constante de Langmuir

$\mathrm{m}$ : massa de nanoadsorvente

M: magnetização

$\mathrm{n}$ : fator de heterogeneidade; número inteiro que representa a ordem de difração

$\mathrm{q}_{\mathrm{e}}$ : quantidade de adsorvato adsorvido; quantidade de soluto adsorvida no equilíbrio

$\mathrm{q}_{\text {máx }}$ : capacidade máxima de adsorção do nanoadsorvente

$\mathrm{q}_{\mathrm{t}}$ : quantidade de soluto adsorvida no tempo $\mathrm{t}$

$\chi$ :susceptibilidade magnética

$R$ : constante dos gases ideais

t: tempo de contato

$T:$ temperatura absoluta

V: volume da solução

$\mathrm{v}_{\mathrm{a}}$ : taxa de adsorção

$v_{e}$ : coeficiente de atividade do $\mathrm{Cr}(\mathrm{VI})$ em solução no equilíbrio

$\mathrm{v}_{\mathrm{d}}$ : taxa de dessorção

$v_{s}$ : coeficiente de atividade do $\mathrm{Cr}(\mathrm{VI})$ adsorvido 
$\beta$ : largura a meia altura do pico de difração; termo referente às camadas adsorvidas

$\theta$ : ângulo do raio incidente; fração de sítios ocupados

$\lambda$ : comprimento de onda

$\Delta G^{0}$ : variação da energia livre de Gibbs 


\section{Sumário}

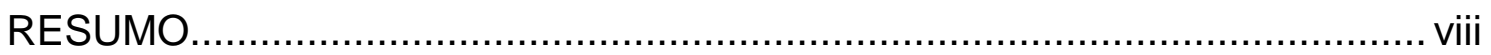

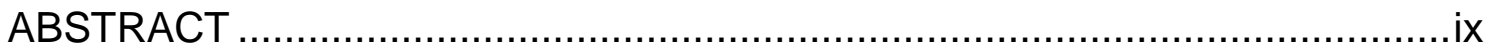

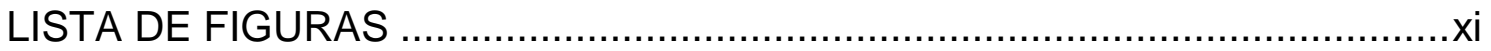

LISTA DE TABELAS ............................................................................

LISTA DE SÍMBOLOS..........................................................................

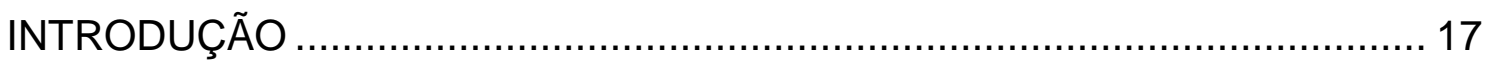

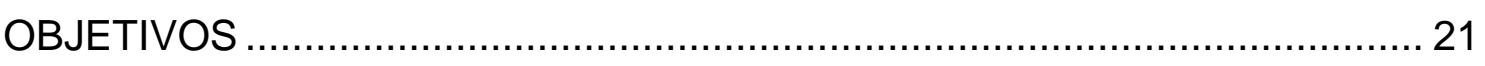

Capítulo 1 - O Cromo ……………………………………………… 22

1.1. O Cromo e o Meio Ambiente ............................................................. 22

1.2. Formas de Remoção do $\mathrm{Cr}(\mathrm{VI})$............................................................ 24

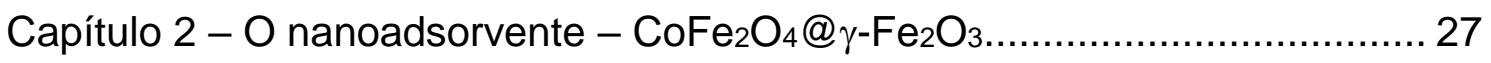

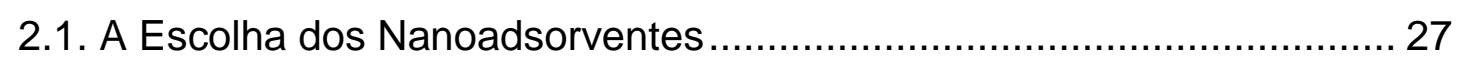

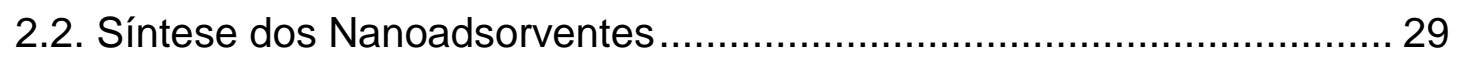

2.3. Caracterização Estrutural e Morfológica ............................................. 32

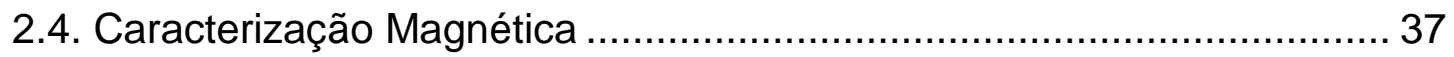

Capítulo 3 - Bateria de Testes de Remoção de $\mathrm{Cr}(\mathrm{VI})$ com os Nanoadsorventes

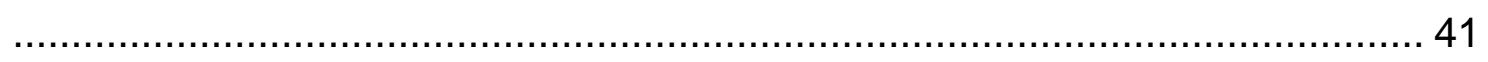

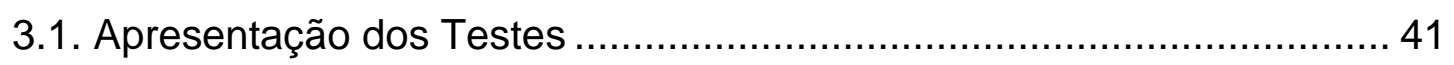

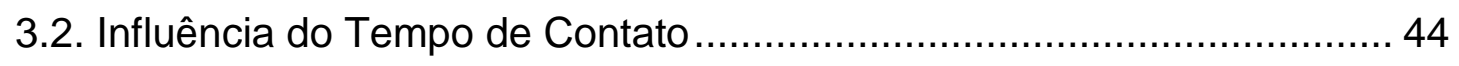

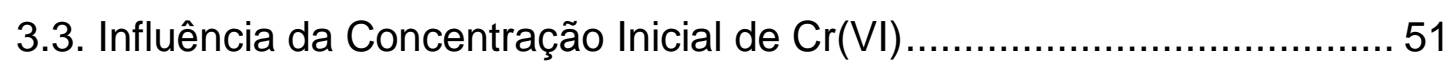

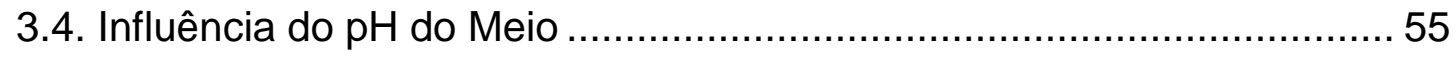

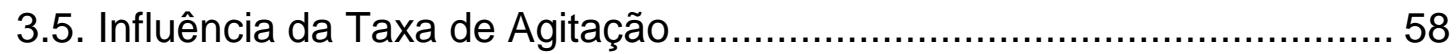

3.6. Estimação de Parâmetros Termodinâmicos à Temperatura Ambiente.. 59

Capítulo 4 - Recuperação e Reutilização dos Nanoadsorventes...................... 62

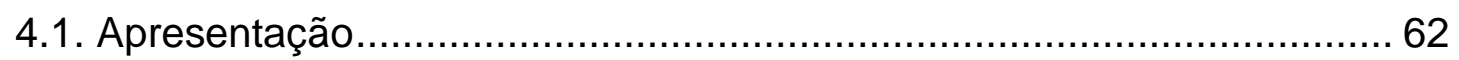

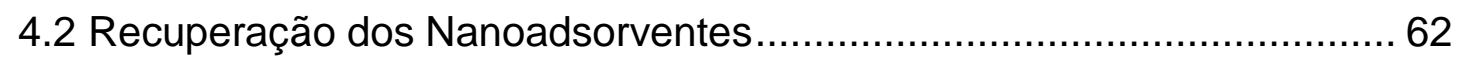

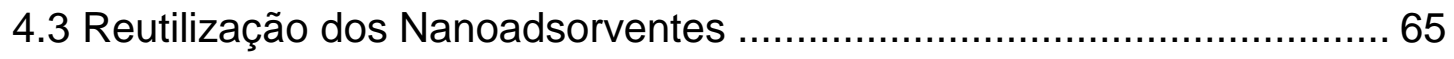

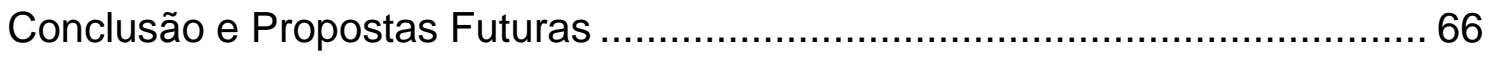

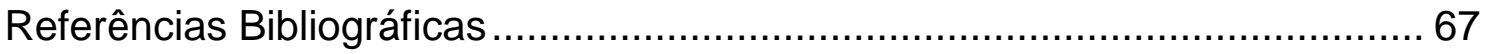




\section{INTRODUÇÃO}

Os materiais foram fundamentais para o desenvolvimento das civilizações. Tanto que alguns períodos evolutivos pelos quais o homem passou são designados em referência à tecnologia de material da época ${ }^{1}$, como Idade da Pedra Lascada, época em que o homem dominava pela primeira vez o uso de madeira, ossos e pedras para fazer utensílios como lanças e arpões; Idade do Bronze época em que o cobre, bronze e ouro começaram a ser utilizados em utensílios; e Idade do Ferro, época em que se alcançou a tecnologia de atingir grandes temperaturas e foi possível fundir o ferro. Atualmente os materiais continuam tendo importante papel, entranhados nas diversas culturas. A presente geração é marcada pelos materiais gerados pela atual tecnologia, que permite, por exemplo, vestuários com propriedades de controle de temperatura e filtros de radiações, impressos em impressoras 3D, aparelhos de comunicação inimagináveis a 200 anos, habitações e transportes leves, mais resistentes e de rápida construção e montagem, indicadores de qualidade de alimentos, sensores diversos e materiais para melhoramento de processos. Vários são os segmentos, influenciados em diferentes graus pela nova Ciência e Tecnologia de Materiais.

A Ciência dos Materiais estuda as relações entre a estrutura de um dado material e suas propriedades elétricas, mecânicas, magnéticas, térmicas e ópticas. Essas propriedades estão profundamente relacionadas à estrutura do material, que é a forma com que os átomos desse material estão dispostos e a interação entre eles ${ }^{1}$. A estrutura afeta diretamente a aplicabilidade do material em escala macrométrica, em situações práticas.

Os materiais nanoestruturados são os materiais fabricados pensando-se na sua estrutura nanométrica (escala de grupos de átomos), para aplicações específicas. Entre as aplicações já citadas, existem também dispositivos para monitoramento, controle e remediação da poluição ambiental ${ }^{2}$.

Uma das definições de poluição é a alteração nas características químicas, biológicas e físicas do ambiente provocada por atividade humana ${ }^{3}$. A poluição ambiental tem ocorrido especialmente a partir do final do século 19 , 
com a expansão industrial gerada pelo rápido desenvolvimento das tecnologias que aumentaram a habilidade do homem de produzir bens para sua qualidade de vida. Cada aspecto da atividade humana está conectado ao meio ambiente ${ }^{4}$. O homem interage e afeta o meio ambiente todos os dias e a poluição gerada por ele influencia não só sua saúde, mas toda a fauna e flora. A poluição pode ocorrer tanto na atmosfera, quanto no meio terrestre quanto no aquoso, ou em todos. Este trabalho se restringirá à poluição em meios aquosos. A água é um dos principais componentes do meio ambiente, indispensável para a vida ${ }^{5}$. A poluição das águas pode vir de diversas fontes ${ }^{6}$, por exemplo: decomposição de resíduos sólidos, águas de drenagem urbana e esgotos sanitários. Esses podem ser provenientes de área comercial, provenientes da atividade pública, domésticos e provenientes da atividade industrial ${ }^{3}$.

A poluição da água proveniente da atividade industrial se apresenta como águas residuais (ou residuárias) industriais. Ela possui três origens: a água usada para resfriamento (águas de refrigeração), efluentes de cozinhas e banheiros da indústria (águas sanitárias) e a água que tem contato direto com a matéria-prima em alguma etapa do processamento do produto (águas de processo) $)^{3}$.

A pressão na indústria para que se diminua a emissão de vários poluentes no ambiente é crescente. No Brasil, a Constituição Federal de 1988 impõe ao Poder Público e à coletividade o dever de defender o meio ambiente ecologicamente equilibrado e preservá-lo para as presentes e futuras gerações, combatendo a poluição em qualquer de suas formas ${ }^{7}$. A Lei N 6.938, de 31 de agosto de 1981, conhecida como Política Nacional do Meio Ambiente, tem como um de seus objetivos o estabelecimento de critérios e padrões de qualidade ambiental. Um dos objetivos da Lei № 9.433, de 08 de janeiro de 1997, é assegurar à atual e às futuras gerações a necessária disponibilidade de água, em padrões de qualidade adequados aos respectivos usos ${ }^{8}$. Ela também prevê o enquadramento dos corpos de água em classes, segundo os usos preponderantes da água ${ }^{8}$. Esse enquadramento ${ }^{9}$ é estabelecido pela Resolução № 357/05 do Conselho Nacional do Meio Ambiente (CONAMA), que é complementada e alterada pela Resolução 430/2011 do CONAMA, que dispõe sobre as condições e padrões de lançamento de efluentes ${ }^{10}$. 
Segundo a Federação de Indústria do DF (Fibra), a participação da indústria na soma do valor de todos os bens e serviços produzidos no Distrito Federal tem crescido, e chegou a 15\% em 2015, envolvendo os setores: Indústria de Transformação, Construção Civil, Serviços de Informação, Indústria Extrativa e Outros Serviços ${ }^{11}$. Nesse sentido, o potencial de contaminação dos recursos hídricos aumenta de forma importante. É um sério desafio na medida em que maiores são as perspectiva de desenvolvimento ${ }^{4}$. A contaminação por metais pesados é um grande problema visto que são substâncias altamente tóxicas e requerem um tratamento especial, já que não são compatíveis com a maioria dos tratamentos biológicos de efluentes existentes ${ }^{12}$.

Visando à minimização dos impactos da poluição, torna-se essencial realizar o tratamento adequado dos efluentes nas fontes de poluição. Esse tratamento dependerá do tipo de poluente no efluente. No caso de metais pesados, existem diversas formas de tratamento, como redução química seguida de precipitação ${ }^{13}$, que gera grandes volumes de lama, e adsorção dos metais ${ }^{14}$. A adsorção, em especial com os adsorventes magnéticos, tem se mostrado um método muito promissor, devido a sua eficiência, custo e não geração de grandes quantidades de resíduo, além de proporcionar a possibilidade de recuperação do metal. Trata-se de uma tecnologia moderna em foco pelos seus impactos positivos ambientais, econômicos e legais ${ }^{4}$.

Inserido nesse contexto, o presente trabalho propõe o desenvolvimento de uma nanotecnologia que visa à remoção de $\mathrm{Cr}(\mathrm{VI})$ de meios aquosos de forma econômica e ambientalmente vantajosa, sem que haja grande geração de resíduos. A remoção será feita através de nanoadsorventes a base de nanopartículas core-shell, com superfície de boa afinidade com o $\mathrm{Cr}(\mathrm{VI})$ e núcleo de alta magnetização de saturação, facilitando a separação química dos nanoadsorventes do meio aquoso. Após a adsorção e a separação química assistida magneticamente, esses nanoadsorventes passarão por processos de recuperação e reutilização.

No Capítulo 1 é discutida a questão do cromo em meios aquosos no meio ambiente e seus limites legais no Brasil, e algumas técnicas comuns de removê-lo de meios aquosos. 
No Capítulo 2 é apresentado o nanoadsorvente proposto neste trabalho, sua síntese e caracterizações estrutural, morfológica e magnética.

O Capítulo 3 é destinado às baterias de testes feitos para investigar a influência de diversas variáveis no processo de adsorção e a capacidade de adsorção do nanoadsorvente, além de estudos da cinética, de isotermas de adsorção e dos parâmetros termodinâmicos.

No capítulo 4 é apresentado o teste de regeneração e reutilização do nanoadsorvente. $O$ objetivo da regeneração do nanoadsorvente consumido é restaurar sua capacidade de adsorção, além de recuperar os valiosos componentes presentes na fase adsorvida.

Por fim, tem-se a conclusão deste trabalho e propostas futuras. 


\section{OBJETIVOS}

O objetivo geral deste trabalho é:

- Propor nanotecnologias visando à remoção de $\operatorname{Cr}(\mathrm{VI})$ de meios aquosos e transformá-los em matéria prima com valor agregado, de forma econômica e ambientalmente vantajosa, sem que haja grande a geração de resíduos.

Os objetivos específicos são:

- Sintetizar, pelo método de coprecipitação, nanoadsorventes magnéticos baseados em nanopartículas do tipo core-shell com núcleo de ferrita de cobalto, coberto com uma camada de maguemita, com potencial de remoção de $\mathrm{Cr}(\mathrm{VI})$;

- Caracterizar os nanoadsorventes sintetizados em termos de estrutura, tamanho médio, morfologia, polidispersão em tamanho e propriedades magnéticas.

- Investigar a influência das variáveis pH, concentração inicial de $\mathrm{Cr}(\mathrm{VI})$, taxa de agitação da solução em contato com os nanoadsorventes no processo de adsorção;

- Investigar a cinética de adsorção dos poluentes, por meio da aplicação de modelos de Pseudo Primeria-Ordem e Pseudo Segunda-Ordem;

- Investigar a termodinâmica de adsorção dos poluentes;

- Avaliar a influência do tamanho cristalino dos nanoadsorventes na capacidade de adsorção dos poluentes;

- Recuperação dos nanoadsorventes usados, de forma que sua capacidade de adsorção seja regenerada;

- Recuperar o poluente que estava disperso no efluente aquoso, e armazená-lo em forma de solução concentrada, visando a utilizá-lo em processos como matéria prima. 


\section{Capítulo 1 - 0 Cromo}

\subsection{O Cromo e o Meio Ambiente}

O cromo é um metal de transição presente no grupo 6 da Tabela periódica e sua toxicidade depende de seu estado de oxidação ${ }^{15}$. 0 cromo não é encontrado livre na natureza, mas em cromatos, dicromatos e sulfatos, por exemplo ${ }^{16}$. Seus estados de oxidação mais comuns na natureza são $\operatorname{Cr}(I I I)$ e $\mathrm{Cr}(\mathrm{VI})^{14}$. O $\mathrm{Cr}(\mathrm{III})$ é um importante elemento traço para seres vivos que metabolizam glicose ${ }^{15,17,18}$, e não é considerado nocivo ao corpo humano em baixas concentrações, mas é nocivo ao meio ambiente. Tanto o $\mathrm{Cr}$ (III) como o $\mathrm{Cr}(\mathrm{VI})$ interferem na captura de elementos essenciais para os vegetais ${ }^{17}$. Já o $\mathrm{Cr}(\mathrm{VI})$ é extremamente tóxico também para 0 homem ${ }^{13}$. Em grandes concentrações e exposições frequentes ao ser humano pode causar doenças perigosas, como câncer ${ }^{19}$. $\mathrm{O} \mathrm{Cr}(\mathrm{VI})$ pode atravessar membranas celulares e oxidar moléculas biológicas ${ }^{14}$. A Agência de Proteção Ambiental dos Estados Unidos colocou o cromo na lista de prioridade máxima de poluentes tóxicos ${ }^{20}$. Em meios oxidantes, o $\mathrm{Cr}(\mathrm{III})$ é lentamente convertido para $\mathrm{Cr}(\mathrm{VI})^{21}$, que permanece em solução ${ }^{17}$.

O $\mathrm{Cr}$ é utilizado em aplicações domésticas e industriais. Na indústria é amplamente utilizado em curtimento de couro, acabamento metálico, fotografia, indústrias têxteis e de preparação cromato, instalações de geração de energia e unidades de fabricação de dispositivos eletrônicos ${ }^{13,14,20}$. O $\mathrm{Cr}(\mathrm{VI})$ também é aplicado em processos de decapagem de metais, galvanização, indústria do aço inoxidável, tintas, corantes, explosivos, cerâmica e papel ${ }^{17}$. Os efluentes dessas indústrias podem conter níveis elevados de cromo, prejudiciais ao meio ambiente se forem descartados sem tratamento. A contaminação da água por efluentes industriais com metais pesados é um problema no mundo todo, que vem crescendo com a rápida industrialização sem planejamento, que libera esses metais pesados tóxicos para corpos receptores ${ }^{14}$.

A atividade humana é responsável por quase todo o $\operatorname{Cr}(\mathrm{VI})$ existente no meio ambiente, que pode chegar a níveis perigosos. A concentração natural 
desse elemento em águas não contaminadas é de cerca de 1,0 a poucos $\mu \mathrm{g} / \mathrm{L}^{16}$. Já em águas contaminadas pode chegar a níveis elevados, como em amostras de água coletadas do rio Hrazdan, na Armenia, de $81,4 \mathrm{mg} / \mathrm{L}^{16}$. Ao contrário de outros poluentes, o cromo não é degradado nem removido por processos naturais ou biológicos ${ }^{15}$. Assim, são necessárias alternativas para a remediação desse problema ambiental.

No Brasil, o CONAMA (Conselho Nacional do Meio Ambiente) tem dentre suas principais competências o estabelecimento das normas e padrões nacionais de controle da poluição, sendo assim o responsável por delimitar a concentração máxima de $\mathrm{Cr}$ em efluentes industriais. Considerando que a saúde e o bem-estar humano, bem como o equilíbrio ecológico aquático, não devem ser afetados pela deterioração da qualidade das águas ${ }^{9}$, a Resolução $n^{\circ}$ 357, de 17 de março de 2005 do CONAMA dispõe sobre a classificação e diretrizes ambientais para o enquadramento dos corpos de água superficiais e estabelece as condições e padrões de lançamento de efluentes ${ }^{9}$. Nela, os padrões de lançamento de efluentes estabelecidos definem o valor máximo de 0,5 mg/L de Cromo Total. Em 2011, essa Resolução foi alterada e complementada pela Resolução 410/2009 e pela 430/2011 do CONAMA, que também dispõe sobre as condições e padrões de lançamento de efluentes. Nesta nova resolução, vigente atualmente, as concentrações máximas estabelecidas de cromo em efluentes são apresentadas na Tabela 1.

\begin{tabular}{cc}
\hline Parâmetro Inorgânico & Valor Máximo \\
\hline \hline $\mathrm{Cr}(\mathrm{VI})$ & $0,1 \mathrm{mg} / \mathrm{L}$ \\
$\mathrm{Cr}(\mathrm{III})$ & $1,0 \mathrm{mg} / \mathrm{L}$
\end{tabular}

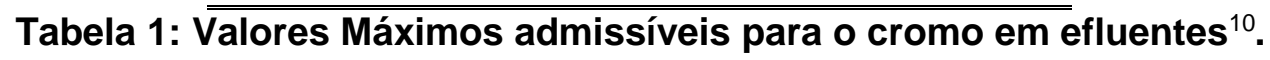

O Art. 29. da resolução 430/2011 do CONAMA determinou que aos empreendimentos e demais atividades poluidoras com licença ambiental expedida até 16/05/2011, poderia ser concedido prazo até 16/05/2014 para adequação às condições e padrões novos ou mais rigorosos estabelecidos na norma. Esse prazo poderá ser prorrogado até 16/05/2017, desde que tecnicamente motivado ${ }^{10}$. 
A Resolução 430/2011 ainda define que

Art. 18. O efluente não deverá causar ou possuir potencial para causar efeitos tóxicos aos organismos aquáticos no corpo receptor, de acordo com os critérios de ecotoxicidade estabelecidos pelo órgão ambiental competente. (p. 5)

Art. $3^{\circ}$ Os efluentes de qualquer fonte poluidora somente poderão ser lançados diretamente nos corpos receptores após o devido tratamento e desde que obedeçam às condições, padrões e exigências dispostos nesta Resolução e em outras normas aplicáveis. (p. 1)

Art. 30. O não cumprimento do disposto nesta Resolução sujeitará os infratores, entre outras, às sanções previstas na Lei no 9.605 , de 12 de fevereiro de 1998, e em seu regulamento. (p. 8)

A Lei no 9.605 , de 12 de fevereiro de $1998^{22}$, que dispõe sobre as sanções penais e administrativas derivadas de condutas e atividades lesivas ao meio ambiente, e dá outras providências, resolve que se o crime ocorrer "por lançamento de resíduos sólidos, líquidos ou gasosos, ou detritos, óleos ou substâncias oleosas, em desacordo com as exigências estabelecidas em leis ou regulamentos", a pena será de reclusão de um a cinco anos, e que incorre nessa mesma pena "quem deixar de adotar, quando assim o exigir a autoridade competente, medidas de precaução em caso de risco de dano ambiental grave ou irreversível."8.

\subsection{Formas de Remoção do $\mathrm{Cr}(\mathrm{VI})$}

Antes de haver o descarte de água contaminada com $\mathrm{Cr}(\mathrm{VI})$ da indústria para o meio ambiente, é necessário que esse efluente seja tratado ${ }^{13}$ para que as concentrações de cromo enquadrem-se às diretrizes estabelecidas pelo CONAMA.

Várias técnicas são utilizadas visando à remoção de metais pesados de efluentes. Uma das principais é a redução química seguida de precipitação ${ }^{13}$. No Brasil ${ }^{16}$, é feita a redução a cromo trivalente, utilizando-se sulfito ou metabissulfito de sódio, e então ele é precipitado com hidróxido de sódio e o precipitado é filtrado. O lodo formado pode ser queimado por "plasma", por meio de um processo desenvolvido pelo IPT - Instituto de Pesquisas Tecnológicas. O resultado é uma cerâmica vitrificada onde o cromo fica 
imobilizado ${ }^{16}$. Essa técnica utiliza equipamento e reagentes de alto custo, além de gerar um grande volume de lama que se torna perigosa para o meio ambiente devido à lixiviação do aterro. Essa técnica também tem uma ineficiente recuperação do metal tratado para reutilização ${ }^{20}$. Outras técnicas existentes são filtração, precipitação eletroquímica, eletrodeposição e adsorção ${ }^{14}$.

A adsorção para remoção de metais pesados de soluções aquosas é um processo onde o adsorvato (metal a ser adsorvido) interage com a superfície do adsorvente (material utilizado para remover os metais) de forma que ao se separar o adsorvente da solução, o adsorvato seja removido com ele, por estar aderido, ou adsorvido, no adsorvente.

O processo de adsorção oferece muitas vantagens em relação às outras técnicas, como por exemplo, disponibilidade de material e rentabilidade, pois podem ser utilizados como adsorventes rejeitos industriais abundantes, como serragem; facilidade de operação e eficiência energética, quando o adsorvente tem muita afinidade com o metal, como carvão ativado, quitosana, casca de frutos e sementes. Outras vantagens da adsorção são independência da gravidade, alta confiabilidade, flexibilidade de design, e maturidade tecnológica4.

Apesar das vantagens, esses adsorventes também têm desvantagens. Por exemplo, alguns geram grandes quantidades de resíduo e o metal removido nem sempre pode ser reaproveitado ${ }^{23}$. Somando a isso, um fator de extrema importância é a dificuldade na separação do adsorvente da solução. Para contornar esse problema, têm sido desenvolvidas tecnologias ambientais baseadas em materiais adsorventes magnéticos, que podem ser separados do meio por aplicação de campo magnético. Nesse contexto, os adsorventes magnéticos encontram grande vantagem aos tradicionais. Esta dissertação foca justamente nesse ponto: desenvolver, caracterizar e aplicar adsorventes magnéticos, porém em nanoescala.

Os nanoadsorventes magnéticos possuem uma grande área superficial onde ocorre a adsorção, por estarem em escala nanométrica. Caso a superfície não tenha afinidade com o adsorvato, ela pode ser funcionalizada com ligantes específicos com capacidade de complexar adsorvato. Por serem magnéticos, a separação do meio aquoso é feita de forma rápida e eficiente ${ }^{20}$, assistida 
magneticamente. Alguns podem inclusive passar por processos de recuperação ${ }^{24}$, para serem reutilizados diversas vezes e o metal adsorvido pode ainda ser recolhido para futuro tratamento e descarte apropriado ou mesmo reutilização. É o caso dos nanoadsorventes estudados neste trabalho.

Neste trabalho, nanoadsorventes à base de nanopartículas de óxidos metálicos magnéticos foram preparados e caracterizados, objetivando a remoção de $\mathrm{Cr}(\mathrm{VI})$ de efluentes aquosos por meio do mecanismo de adsorção, seguida da separação química assistida magneticamente. 


\section{Capítulo 2 - 0 nanoadsorvente - $\mathrm{CoFe}_{2} \mathrm{O}_{4} @ \gamma-\mathrm{Fe}_{2} \mathrm{O}_{3}$}

\subsection{A Escolha dos Nanoadsorventes}

Um dos objetivos principais desde trabalho é a remoção do $\operatorname{Cr}(\mathrm{VI})$ de águas residuárias. Para isso foram sintetizados nanoadsorventes com potencial para adsorver e remover o $\mathrm{Cr}(\mathrm{VI})$ de soluções aquosas verdadeiras.

O método, que combina adsorção em nanopartículas com separação magneticamente assistida, oferece as vantagens de fácil aplicação, rapidez, bom custo-benefício e baixa geração de resíduos.

$\mathrm{Na}$ literatura, as principais nanotecnologias para remoção de cromo por adsorção seguida de separação magnética empregam nanopartículas de maguemita e magnetita como adsorvente, devido a sua grande afinidade pelo $\mathrm{Cr}(\mathrm{VI})^{25}$. Neste trabalho, objetivando-se principalmente aumentar a eficiência do processo de separação química magneticamente assistida, buscou-se como alternativa a utilização do nanoadsorvente à base de ferrita de cobalto $\mathrm{CoFe}_{2} \mathrm{O}_{4}$, que, além de ser um magneto duro, possui magnetização de saturação sob temperatura ambiente muito mais elevada que a maguemita ${ }^{25}$. Contudo, nanopartículas de ferrita de cobalto sofrem dissolução em pHs ácidos, tornando impossível sua utilização.

Para contornar esse problema, nesta dissertação é proposto um nanoadsorvente à base de nanopartículas do tipo core-shell $\mathrm{CoFe}_{2} \mathrm{O}_{4} @ \gamma-\mathrm{Fe}_{2} \mathrm{O}_{3}$ nas quais um núcleo correspondente à ferrita de cobalto é envolto por uma fina camada superficial de maguemita, que previne a dissolução do nanoadsorvente em meio ácido, além de ter considerável afinidade com o $\operatorname{Cr}(\mathrm{VI})(\text { Figura } 1)^{26}$. 

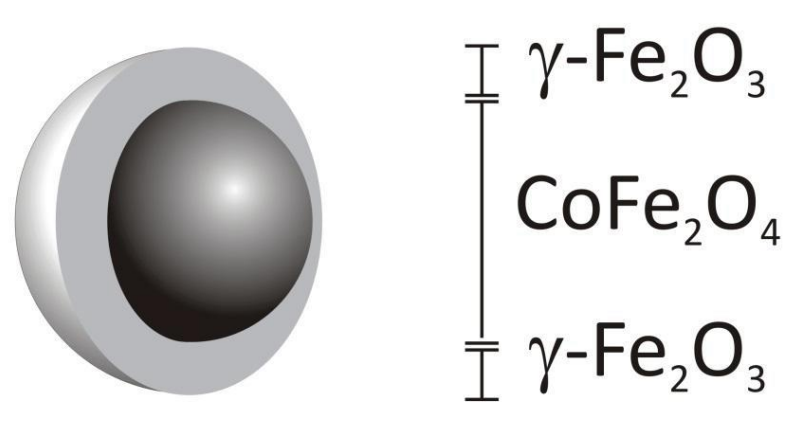

Figura 1: Estrutura da nanopartícula. De acordo com o modelo core-shell: um núcleo de ferrita de cobalto $\left(\mathrm{CoFe}_{2} \mathrm{O}_{4}\right)$ recoberto por uma superfície de maguemita $\left(\gamma-\mathrm{Fe}_{2} \mathrm{O}_{3}\right)^{26}$.

Por estarem na dimensão nanométrica, essas nanopartículas têm a característica de possuir uma grande área superficial com poucos gramas de partículas. A figura 2 ilustra a razão entre a área superficial e o volume. Como se pode verificar, à medida que o diâmetro da partícula diminui, a razão superfície/volume aumenta acentuadamente. Na prática, isso se traduz como uma maior eficiência de adsorção, uma vez que a superfície específica do adsorvente torna-se maior.

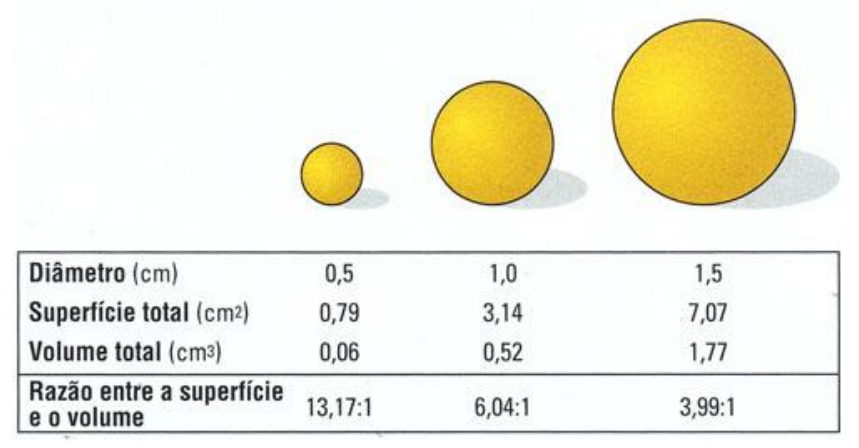

Figura 2: Relação entre a área e o volume de um objeto de forma regular. Para um mesmo volume de esferas de um mesmo tamanho, maior será a soma das áreas superficiais das esferas quanto menores elas forem ${ }^{27}$.

É na superfície da partícula que ocorre a adsorção. Cada local onde há ou pode haver a interação com o adsorvato é chamado de um sítio de adsorção. Quanto maior a área superficial, mais sítios de adsorção estarão disponíveis. Ainda, quanto menores forem as partículas de uma dada massa, mais sítios de adsorção existirão, logo, maior possibilidade de ocorrer adsorção. 
Por outro lado, com relação às propriedades magnéticas, quanto menor a partícula, menor sua magnetização. Como a separação é conduzida magneticamente, espera-se que uma partícula maior seja separada mais rapidamente que uma partícula menor. Nesse sentido, é fundamental encontrar um balanço entre as propriedades magnéticas e a capacidade de adsorção dos nanoadsorventes.

Para investigar a real influência do tamanho do nanoadsorvente na eficácia da adsorção, todos os testes de adsorção de $\mathrm{Cr}(\mathrm{VI})$ foram feitos com nanoadsorventes de dois tamanhos diferentes.

A seguir são apresentadas a síntese e as caracterizações estrutural, morfológica e magnética dos nanoadsorventes investigados neste trabalho.

\subsection{Síntese dos Nanoadsorventes}

Os nanoadsorventes foram sintetizados empregado-se o método hidrotérmico baseado em reações de policondensação, que envolvem a coprecipitação de íons metálicos em meio alcalino ${ }^{26}$. Algumas vantagens desse método são a relativamente baixa polidispersão de tamanho das partículas resultantes, baixa temperatura de síntese em relação a outros métodos métodos, baixo custo do equipamento para produção e possibilidade de sintetizar grandes quantidades.

Primeiro foi preparado o nanoadsorvente de maior tamanho, WCo1. Em um béquer foi aquecida até a fervura uma solução de $2 \mathrm{~L}$ de $\mathrm{NaOH}$ a $2 \mathrm{~mol} / \mathrm{L}$ (Figura 3(a)) no agitador magnético Quimis. Em seguida, foi adicionada rapidamente uma mistura das seguintes soluções: uma de $\mathrm{FeCl}_{2}$ e outra de $\mathrm{Co}\left(\mathrm{NO}_{3}\right)_{3}$, ambas a $0,5 \mathrm{~mol} / \mathrm{L}$ em uma proporção de 2:1 (Figura 3(b)). O sistema permaneceu em agitação (velocidade no 9 10) e fervura durante 30 minutos (Figura 3(c)). 

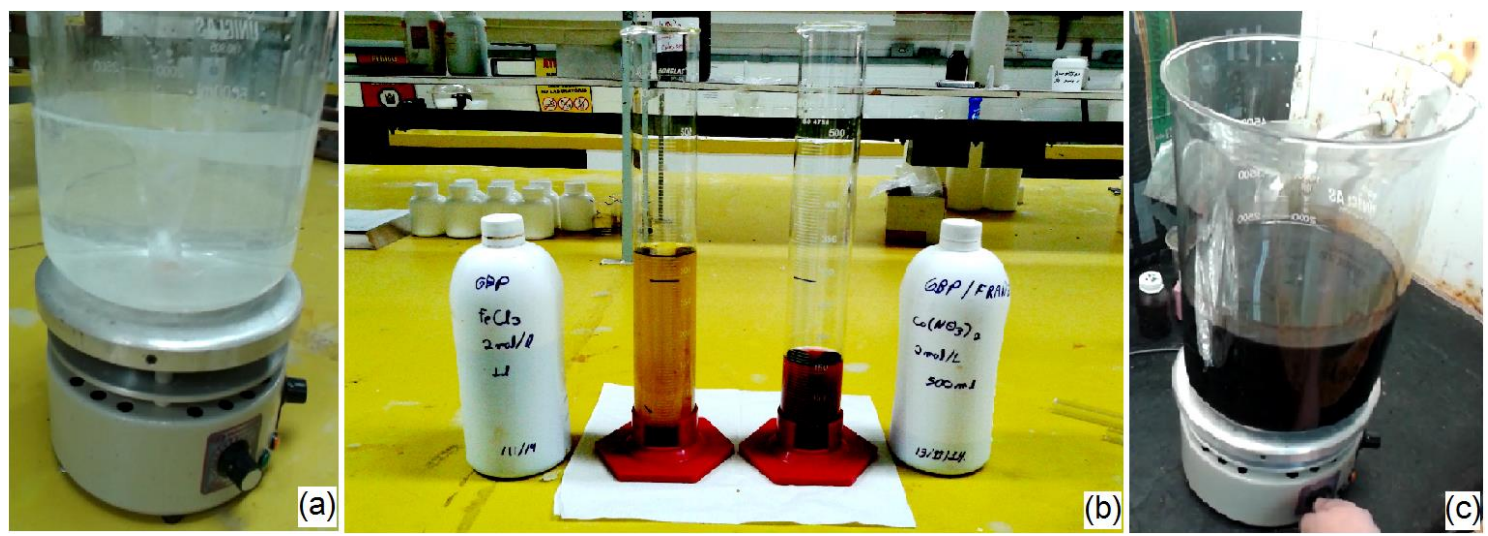

Figura 3: Fotos de momentos da síntese do nanoadsorvente WCo1. (a) solução de $\mathrm{NaOH} 2 \mathrm{~mol} / \mathrm{L}$ em fervura e agitação; (b) soluções de $\mathrm{FeCl}_{2}$ e de $\mathrm{Co}\left(\mathrm{NO}_{3}\right)_{3}$ que serão adicionadas ao NaOH; (c) Soluções logo após a adição.

Com a supersaturação das espécies iniciais, ocorre a condensação química dos íons $\mathrm{Co}^{2+}$ e $\mathrm{Fe}^{3}$ em meio alcalino, ou coprecipitação, formando pequenos sólidos estáveis. A equação 1 apresenta o balanço global da coprecipitação:

$$
\mathrm{Co}_{(a q)}^{2+}+2 \mathrm{Fe}_{(a q)}^{3+}+8 \mathrm{OH}_{(a q)}^{-} \rightarrow \mathrm{CoFe}_{2} \mathrm{O}_{4(s)}+4 \mathrm{H}_{2} \mathrm{O}_{(l)} .
$$

eq. 01

Esse mecanismo é conhecido como nucleação. A esse "núcleo" ou germe cristalino formado, os íons da solução foram sendo associados, aumentando o tamanho do germe. Esse fenômeno é conhecido como crescimento cristalino ${ }^{28}$. A nucleação e o crescimento cristalino acontecem simultaneamente. Um ou outro pode ser favorecido por diversos fatores, como a a taxa de agitação, já que a interação entre os íons depende da colisão entre eles. Quando a solução é agitada rapidamente, é favorecida a nucleação, resultando em muitas partículas pequenas. Por outro lado, se a solução for agitada com menor taxa ou ficar mais em repouso, é favorecido o crescimento cristalino, gerando relativamente menos partículas, porém de maiores tamanhos médios.

Outro fator que influencia o tamanho das partículas é a natureza da base utilizada $^{29}$. Para a síntese do nanoadsorvente de menor tamanho, FPCo1, o procedimento foi o mesmo, com a diferença que a base utilizada foi a metilamina $\left(\mathrm{CH}_{3} \mathrm{NH}_{2}\right)$, menos forte do que o NaOH. A força da base age significativamente no tamanho das nanopartículas porque a função dela é 
desprotonar os aquocátions metálicos da solução para que possam ligar-se, promovendo reações de polimeraização inorgânica que levam ao crescimento cristalino. Logo, mantendo-se constantes os demais parâmetros, quanto maior for a força da base, maiores serão as partículas formadas ${ }^{29}$.

O resultado das sínteses até este ponto, são as nanopartículas em forma de precipitado, com as superfícies carregadas negativamente. Em seguida, nos dois casos, os sistemas permaneceram em repouso até atingirem temperatura ambiente (Figura 4(a)) sendo que o sobrenadante foi retirado posteriomente. Logo após foram feitas duas lavagens que consistem basicamente em colocar água destilada, misturar, esperar que as partículas se depositassem no fundo com auxílio de um ímã, e remover o sobrenadante. Em seguida, com as partículas em repouso, foi adicionada uma solução de $\mathrm{HNO}_{3}$ a $2 \mathrm{~mol} / \mathrm{L}$ até cobrir as partículas, permanecendo assim por cerca de $12 \mathrm{~h}$. A função do ácido foi degradar as partículas menores e outros óxidos e materiais secundários, além de reduzir o $\mathrm{pH}$ e permitir a troca de íons, para que pudesse ser feito o tratamento superficial das nanopartículas. Finalmente, mais uma lavagem foi feita.

$O$ tratamento superficial resume-se na adição de solução $0,5 \mathrm{~mol} / \mathrm{L}$ de $\mathrm{Fe}\left(\mathrm{NO}_{3}\right)_{3}$. O sistema é deixado em fervura por 15 minutos (Figura 4(b)), e em seguida são feitas sucessivas lavagens com água destilada e acetona (Figura 4(c)). Nesse ponto, o material resultante pode alcançar equilíbrio ideal de uma solução coloidal, um ferrofluido (Figura 4(d)). A acetona foi utilizada por ser solúvel na água e não solubilizar no ferrofluido, facilitando a lavagem: ao se misturar água destilada e acetona às partículas, o excesso de íons resultantes da síntese como sódio, cloreto e nitrato, e clusters que não formaram partículas, são solubilizados e ficam na camada sobrenadante, que pode ser facilmente retirada e descartada. 


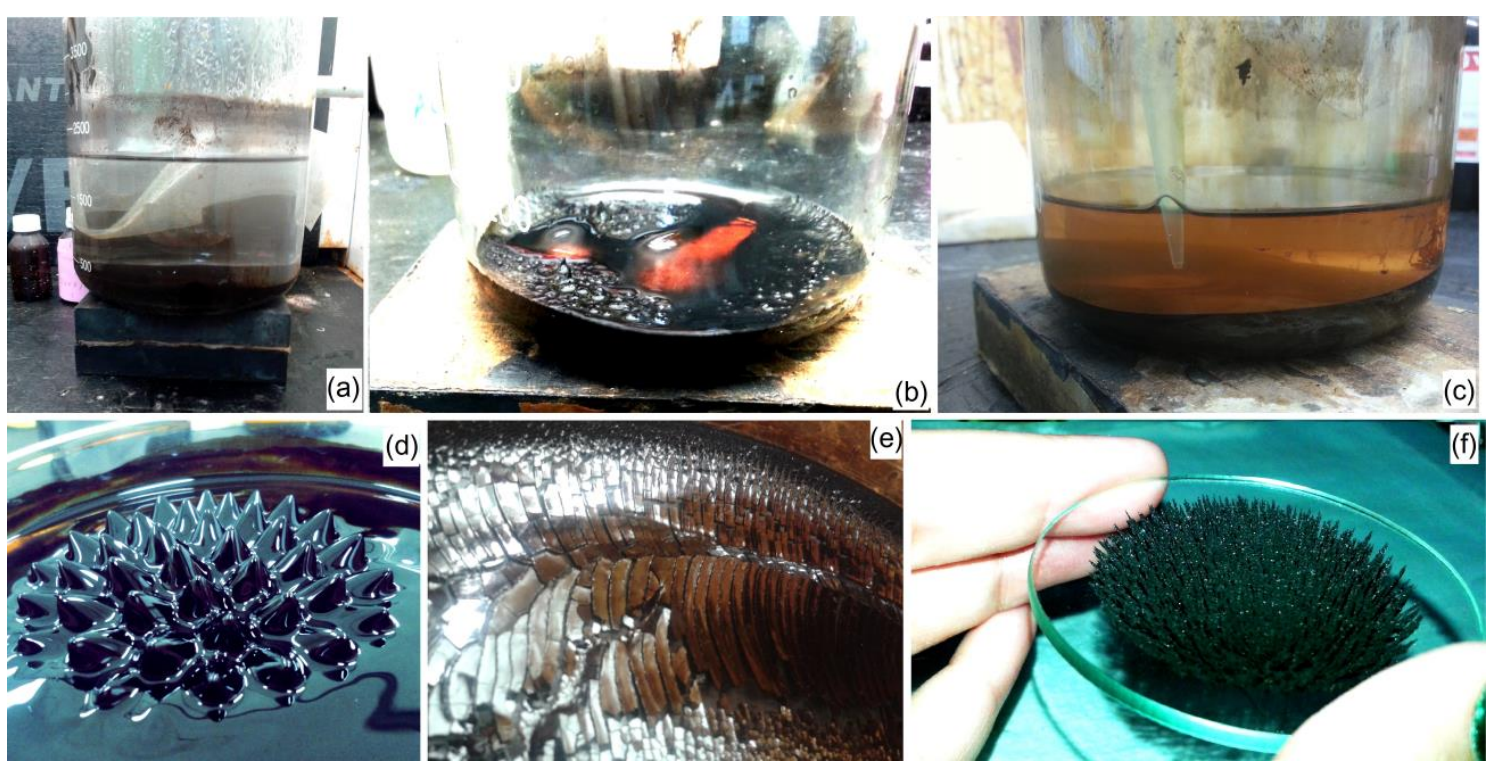

Figura 4: Fotos de etapas da síntese dos nanoadsorventes. (a) sistema com nanopartículas recém formadas em repouso; (b) tratamento superficial das nanopartículas com $\mathrm{Fe}\left(\mathrm{NO}_{3}\right)_{3}$; (c) lavagem dos nanoadsorventes; (d) ferrofluido formado no processo de síntese dos nanoadsorventes; (e) precipitado seco; (f) nanoadsorventes prontos.

Esse tratamento superficial, que visa a formação de uma camada de maguemita, foi feito para que fosse possível utilizar os nanoadsorventes na remoção de $\mathrm{Cr}(\mathrm{VI})$ em baixos valores de $\mathrm{pH}$, já que a maguemita é estável em baixos valores de $\mathrm{pH}^{30}$. Se não fosse esse tratamento superficial, as partículas se degradariam naturalmente em meio ácido, como na equação a seguir.

$$
\mathrm{CoFe}_{2} \mathrm{O}_{4}+8 \mathrm{H}_{3} \mathrm{O}_{(a q)}^{+} \rightarrow \mathrm{Co}_{(a q)}^{2+}+2 \mathrm{Fe}_{(a q)}^{3+}+12 \mathrm{H}_{2} \mathrm{O}_{(l)},
$$

Após esse processo, o precipitado foi seco (Figura 4(e)), macerado com auxílio do almofariz e pistilo, resultando nos nanoadsorventes a serem empregados (Figura 4(f)).

\subsection{Caracterização Estrutural e Morfológica}

Os nanoadsorventes FPCo1 e WCo1 foram caracterizados estruturalmente utilizando a técnica de difração de raios $X(D R X)$ com 0 difratômetro D8 Focus-Bruker, operado a 40kV/30mA com radiação $\mathrm{Cu}-\mathrm{K} \alpha$ 
$(\lambda=0,1541 \mathrm{~nm})$ e monocromador de Ge 111 . Nessa técnica, raios $X$, que possuem comprimentos de onda na mesma ordem que as distâncias interatômicas, são incididos na amostra e são desviados em diversas direções, ao interagir com as camadas da rede cristalina da amostra, gerando um padrão de difração específico para a amostra (Figura 5). Assim, é possível se determinar a estrutura cristalina da mesma. A lei de Bragg (equação 03) relaciona a distância interplanar $d$ com o comprimento de onda $\lambda$ e 0 ângulo $\theta$ do raio incidente. $n$ é um número inteiro que representa a ordem de difração.

$$
n \lambda=2 d \operatorname{sen}(\theta),
$$

eq. 03

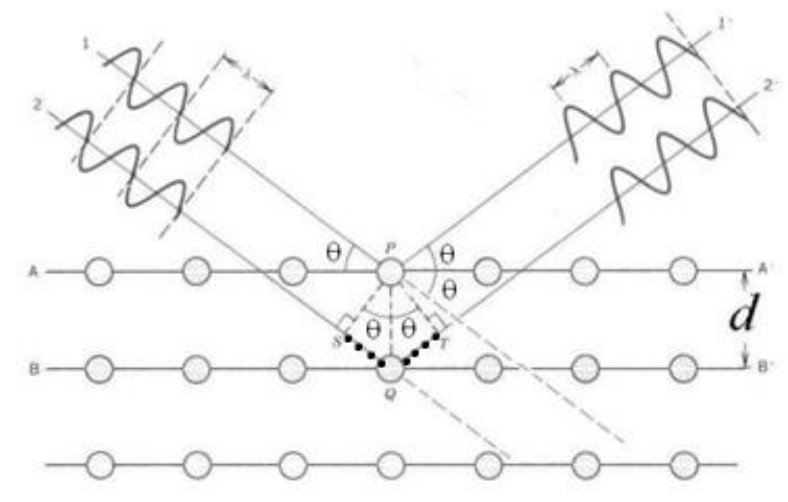

Figura 5: Lei de Bragg e caminhos dos raios difratados através dos planos cristalográficos de uma amostra ${ }^{31}$.

em que $2 d \operatorname{sen}(\theta)$ é a diferença entre os comprimentos das trajetórias das duas ondas incididas, em pontilhado na figura 5. Se essa diferença de caminho óptico for igual a um número inteiro de comprimentos de onda, irá ocorrer uma interferência construtuva, detectada pelo sensor do aparelho de difratometria. Em todos os outros casos a interferência será mais ou menos destrutiva, sendo totalmente destrutiva quando a diferenca entre os caminhos ópticos for igual a algum número inteiro ímpar de meios comprimentos de onda.

Os resultados da análise de difratometria de raios $X$ das duas amostras são apresentados na figura 6 . Os difratogramas foram obtidos dentro do intervalo $20^{\circ}<2 \theta$ com ppasso de $0,05^{\circ}$ e taxa de varredura de $0,1 \% \mathrm{~min}$. Os picos de alta intensidade representam a interferência construtiva nos planos cristalinos. Seus índices de Miller estão indexados na figura. 

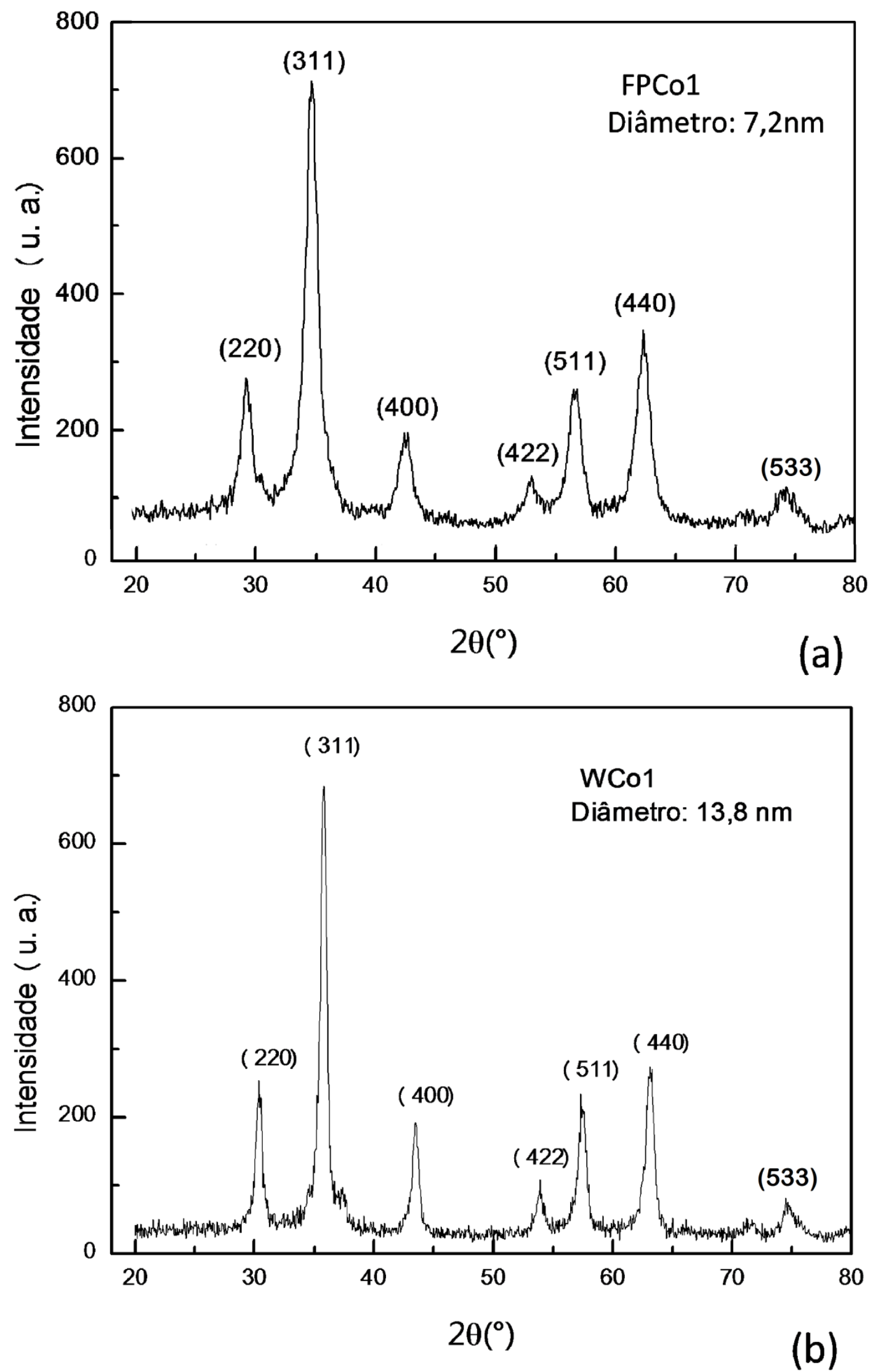

Figura 6: Difratogramas de raios X das amostras dos nanoadsorventes FPCo1 (a) e WCo1 (b). 
As distâncias interplanares possuem uma dependência com os índices hkl, que podem ser expressas pela equação 04, no caso de simetrias cúbicas.

$$
d_{h k l}=\frac{a}{\sqrt{h^{2}+k^{2}+l^{2}}}
$$

Os parâmetros de difração confirmam a formação de partículas de ferrita com uma estrutura do tipo espinélio visto que o valor médio de aresta corresponde a 0,833 nm e 0,834 nm, para as amostras FPCo1 e WCo1, respectivamente, em excelente acordo com 0 valor padrão da American Society for Testing Materials (ASTM) cujo valor é $0,833 \mathrm{~nm}$.

Para determinar o diâmetro médio das partículas, empregou-se a equação de Scherrer.

$$
D=\frac{\mathrm{K} \lambda}{\beta \cos \theta},
$$

Onde:

$D$ - diâmetro médio das partículas;

$\mathrm{K}$ - constante que depende da forma das partículas (esfera $=0,94$ );

$\lambda$ - comprimento de onda da radiação eletromagnética;

$\beta$ (20) - largura na metade da altura do pico de difração, preferencialmente o mais intenso;

$\theta$ - ângulo de difração.

Infere-se da equação de Scherrer, que o diâmetro obtido para os nanoadsorventes estudados foi de 7,2 nm para FPCo1 e de 13,8 nm para WCo1.

A morfologia e a dispersão de tamanho dos nanoadsorventes foram caracterizadas por Microscopia Eletrônica de Transmissão (TEM). As micrografias de TEM (Figura 7) foram obtidas com microscópio JEOL JEM2100 (200 kV), no Instituto de Física da Universidade Federal de Goiás. 

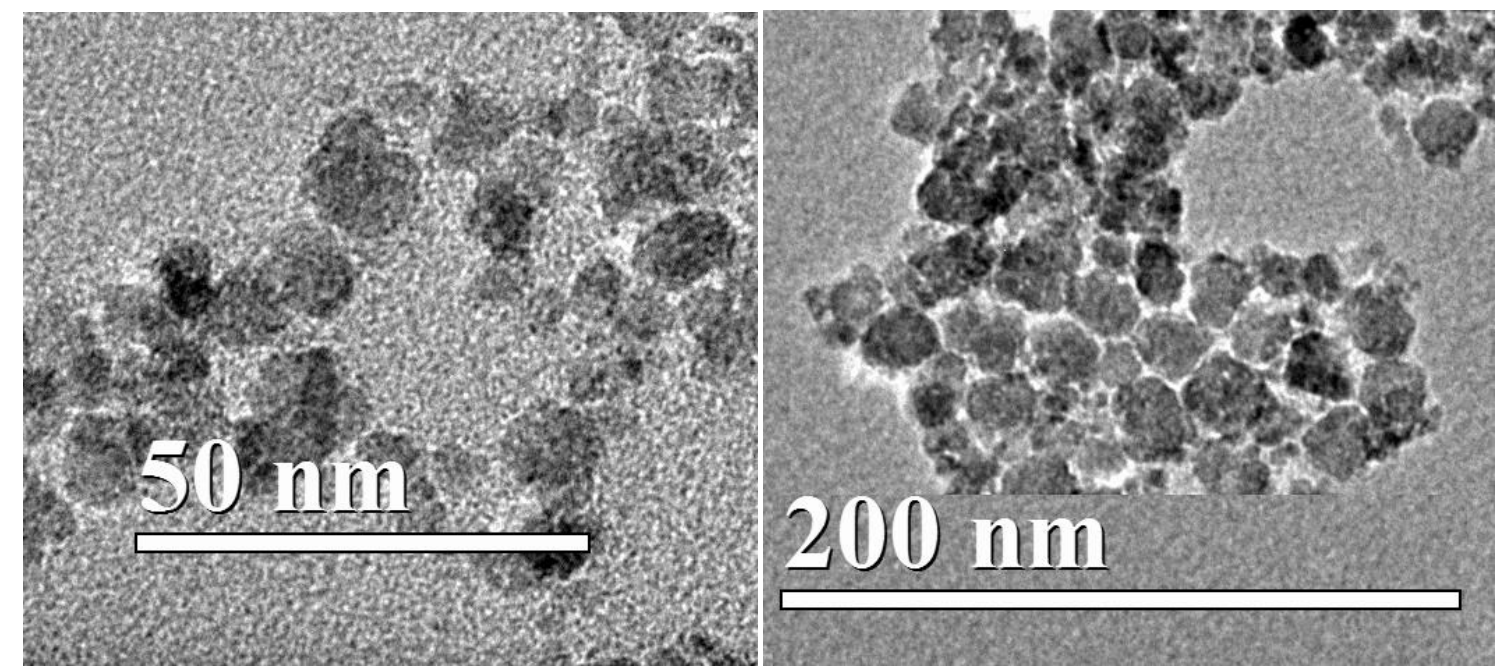

Figura 7: Imagem obtida por Microscopia Eletrônica de Transmissão (TEM) dos nanoadsorventes FPCo1 (a primeira) e WCo1 (a segunda).

As imagens geradas pela TEM indicam que as nanopartículas têm geometria aproximadamente esférica e apresentam certa polidispersão em tamanho. A polidispersão indica a distribuição média de tamanho das nanopartículas. Valores de polidispersão menores que 0,2 indicam boa estabilidade num colóide ${ }^{32}$, o que sugere muito baixa polidispersão de tamanho das partículas. Para determinar essa polidispersão, cerca de 500 partículas tiveram seus diâmetros medidos e gerou-se um histograma de tamanho das partículas (Figura 8), utilizando o programa Origin.
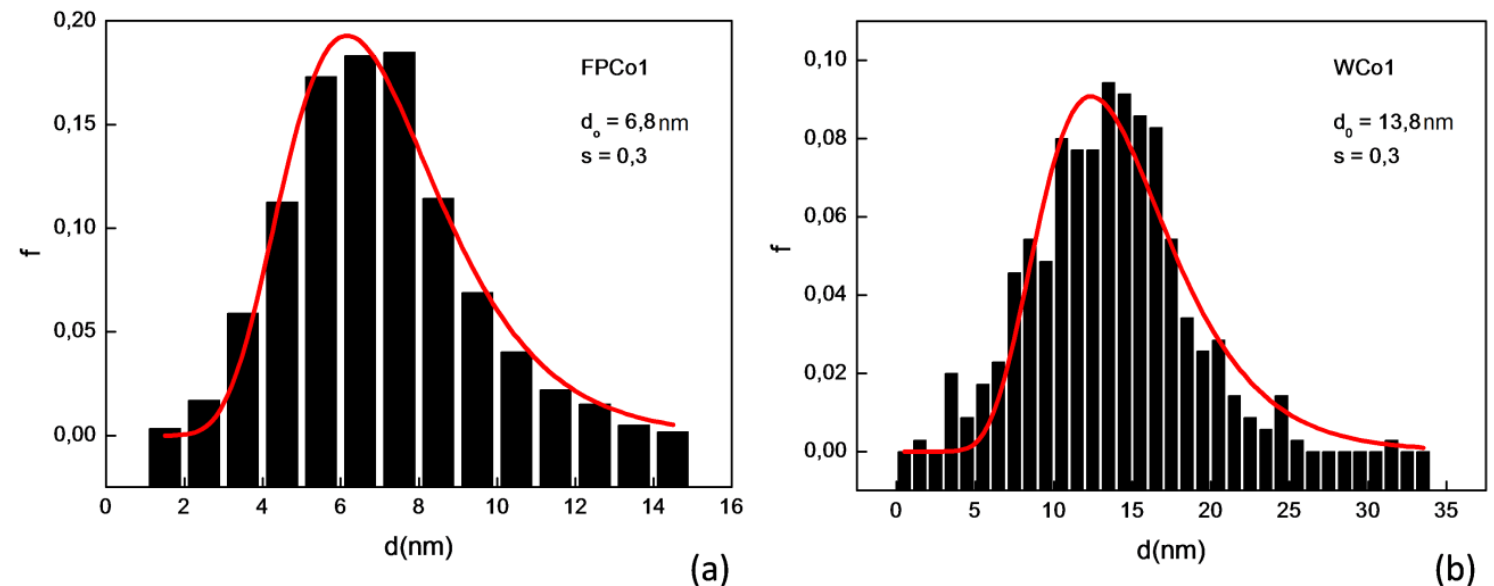

(a)

(b)

Figura 8: Histograma de tamanhos das amostras dos nanoadsorventes FPCo1 (a) e WCo1 (b) ajustados com a função de distribuição log-normal.

Os histogramas da figura 8 foram mais bem ajustados a função de uma distribuição do tipo log-normal. Dessa análise, o diâmetro característico e a polidispersão obtidos para os nanoadsorventes FPCo1 e WCo1 foram de 
6,8 nm, 0,3 e 13,8 nm, 0,3, respectivamente, valores típicos para o método de síntese utilizado para este tipo de amostra.

A Tabela 2 lista os valores dos diâmetros médios dos nanoadsorventes com as respectivas polidisperões.

\begin{tabular}{ccc}
\hline \hline Parâmetro & FPCo1 & WCo1 \\
\hline \hline Diâmetro médio (DRX) & $7,2 \mathrm{~nm}$ & $13,8 \mathrm{~nm}$ \\
Diâmetro médio (TEM) & $6,8 \mathrm{~nm}$ & $13,8 \mathrm{~nm}$ \\
Polidispersão & 0,3 & 0,3 \\
\hline
\end{tabular}

Tabela 2: Resumo dos resultados de caracterização morfológica dos nanoadsorventes.

\subsection{Caracterização Magnética}

Para investigar as propriedades magnéticas dos nanoadsorventes na adsorção do $\mathrm{Cr}(\mathrm{VI})$, foram feitas medidas de magnetização/susceptibilidade magnética sob temperatura ambiente com o magnetômetro PPMS (Physical Property Measurment System - Quantum Design) de amostra vibrante (modo VSM - vibrating sample magnetometer). 


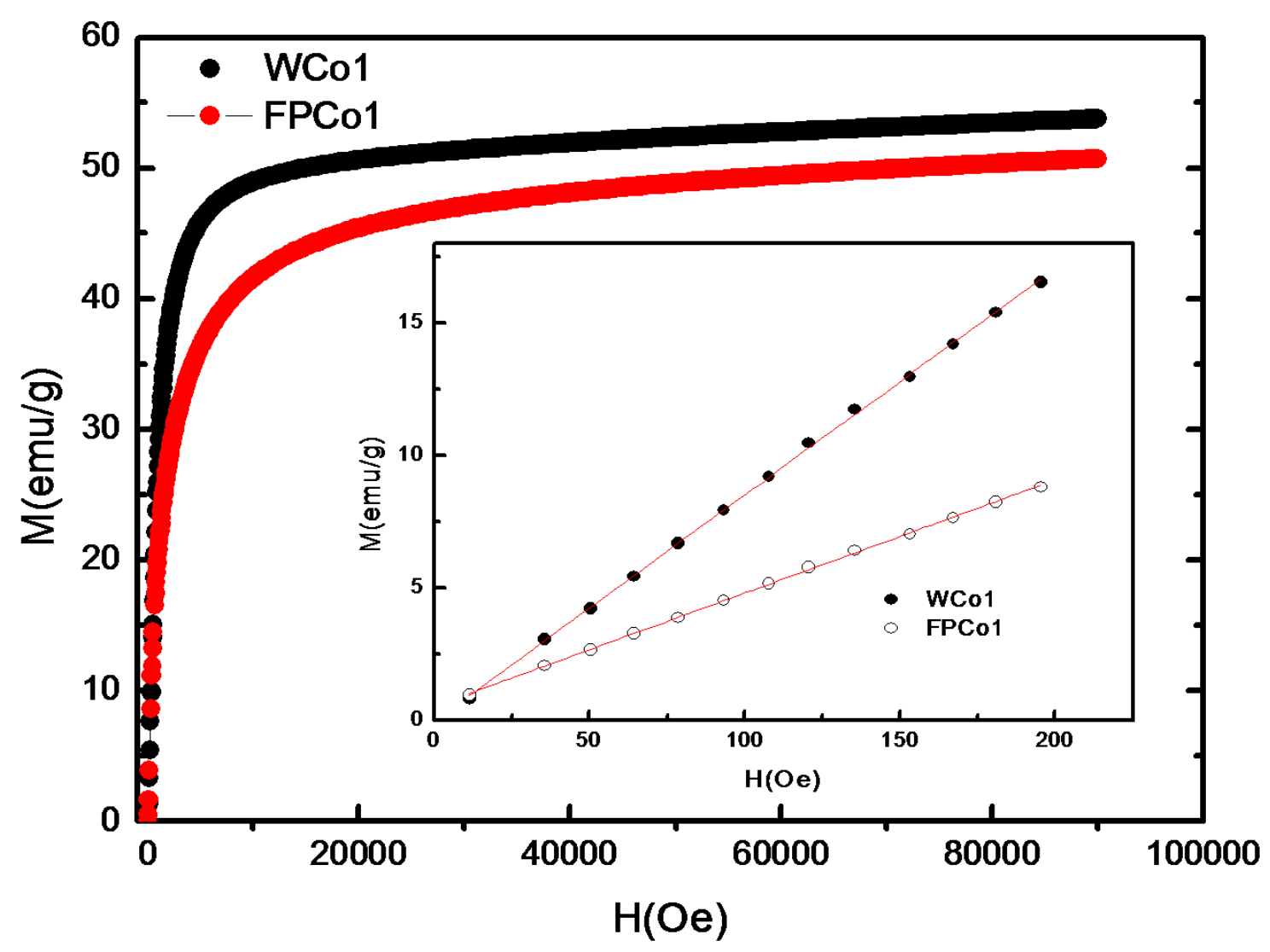

Figura 9: Curva de magnetização, sob temperatura ambiente, dos nanoadsorventes WCo1 e FPCo1. No inset é feita uma ampliação de escala na região próxima à origem, objetivando-se determinar a susceptibilidade magnética dos nanoadsorventes por meio do ajuste linear dos pontos experimentais.

Na figura 9 são mostradas as curvas de magnetização à temperatura ambiente dos nanoadsorventes elaborados, a partir das quais pode se verificar que a magnetização de saturação do WCo1 é maior do que a do FPCo1, como esperado, por apresentar maior tamanho médio. Os elevados valores de magnetização de saturação revelam que ambos nanoadsorventes são fortemente magnéticos ${ }^{33}$.

No caso da separação química assistida magneticamente, o parâmetro magnético mais importante a ser considerado é a susceptibilidade magnética $(\chi)$ do nanoadsorvente, que corresponde a sua capacidade de se magnetizar na presença de um campo magnético, de acordo com a equação:

$$
\chi=\mathrm{M} / \mathrm{H}
$$

eq. 5 
em que $\mathrm{M}$ e $\mathrm{H}$ correspondem à magnetização e ao módulo de campo externo aplicado, respectivamente. A susceptibilidade magnética dos nanoadsorventes investigados foi determinada pelo ajuste linear dos dados de magnetização a baixo campo aplicado, de acordo com a equação anterior. A Tabela 3 lista os valores de magnetização de saturação e de susceptibilidade magnética dos nanoadsorventes elaborados.

\begin{tabular}{ccc}
\hline Parâmetro & FPCo1 & WCo1 \\
\hline \hline Magnetização de saturação (emu/g) & 50,7 & 53,8 \\
Susceptibilidade magnética & 0,043 & 0,086 \\
\hline \hline
\end{tabular}

Tabela 3: Resumo dos resultados de caracterização magnética dos nanoadsorventes.

Para investigar qualitativamente o efeito das propriedades magnéticas na separação dos nanoadsorventes da solução, foi observado o comportamento de misturas dos nanoadsorventes com água, sem e com a utilização de ímãs. Quantidades iguais em massa de cada nanoadsorvente permaneceram em agitação a 500 RPM durante 5 minutos em água deionizada em pH nêutro. Logo em seguida foram colocados em repouso e fotos foram capturadas no decorrer do tempo, até 5 minutos (Figura 10).

As cores escuras das soluções na figura 10 (a) são referentes às partículas que permaneceram em suspensão. Desde os primeiros segundos, os nanoadsorventes WCo1 interagiram fortemente magneticamente entre si, coagulando-se rapidamente no centro do fundo do erlenmeyer (Figura 10(a)), enquanto a mistura contendo FPCo1 ficou durante mais tempo homogênea. Já com o auxílio do ímã, a separação foi feita em poucos segundos e não houve diferença significativa entre os nanoadsorventes (Figura 10(b)). 


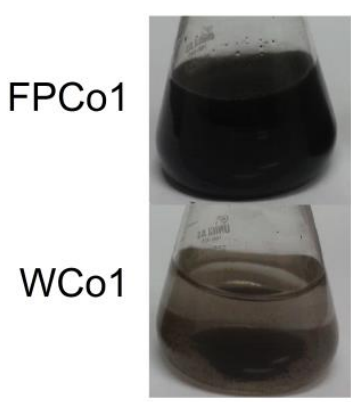

0 min.

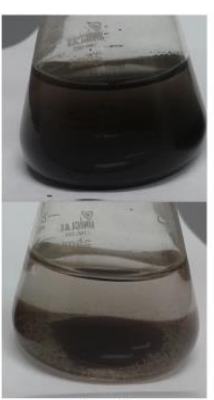

$1 \mathrm{~min}$.

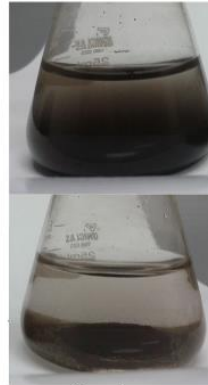

$3 \mathrm{mim}$.

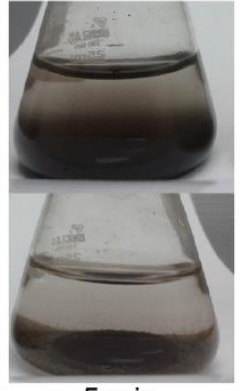

$5 \min$

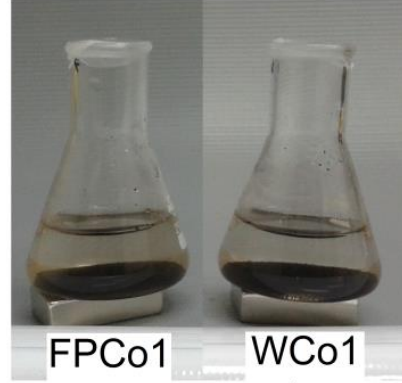

poucos segundos com ímã (b)

Figura 10: Comparação entre a separação química dos nanoadsorventes FPCo1 e WCo1 no decorrer do tempo sem auxílio do ímã (a) e com o auxílio do ímã (b).

Se, por um lado, a maior susceptibilidade magnética do nanoadsorvente WCo1 permite uma separação mais rápida dos nanoadsorventes com $\mathrm{Cr}(\mathrm{VI})$ da solução, por outro lado pode prejudicar a capacidade de adsorção, pois as partículas tendem a se aglomerar, devido à forte interação dipolar magnética, fazendo com que a área superficial disponível para a adsorção seja reduzida, diminuindo a porcentagem de remoção do $\mathrm{Cr}(\mathrm{VI})^{20}$. O ideal é contrabalançar as propriedades magnéticas com a capacidade de adsorção dos materiais, visando à maior eficiência no processo de remoção, através da ponderação da influência dessas características, feita a partir dos resultados dos testes de adsorção. 


\section{Capítulo 3 - Bateria de Testes de Remoção de $\mathrm{Cr}(\mathrm{VI})$ com os Nanoadsorventes}

\subsection{Apresentação dos Testes}

Um dos objetivos deste trabalho é determinar as melhores condições de utilização dos nanoadsorventes sintetizados para remover o $\operatorname{Cr}(\mathrm{VI})$. Este capítulo apresenta os testes de adsorção para investigar essas condições, incluindo como e quais os fatores influenciam na adsorção do $\mathrm{Cr}(\mathrm{VI})$.

Todos os testes foram realizados no Laboratório 3Nano, localizado no Instituto de Física da Universidade de Brasília.

Em todos os testes foram utilizados os mesmos materiais, listados abaixo:

- Solução estoque de cromato de potássio $\left(\mathrm{K}_{2} \mathrm{CrO}_{4}\right)$ a $1000 \mathrm{mg} / \mathrm{L}$ em $\mathrm{Cr}(\mathrm{VI})$;

- Água deionizada (tipo I), para diluir a solução mãe, alcançando assim concentrações apropriadas para cada teste;

- Soluções aquosas de $\mathrm{NaOH}$ e $\mathrm{HNO}_{3}$, ambas a $0,1 \mathrm{~mol} / \mathrm{L}$, para controlar o valor de $\mathrm{pH}$ em cada teste;

- $0,075 \mathrm{~g}$ de nanoadsorvente em cada amostra de $15 \mathrm{~mL}$ de cada teste $(5 \mathrm{~g} / \mathrm{L}$ de nanoadsorvente).

As soluções foram preparadas com valores de $\mathrm{pH}$ e concentração inicial $\left(C_{0}\right)$ de $\operatorname{Cr}(\mathrm{VI})$ determinados para cada teste, com volume final de $15 \mathrm{~mL}$ em cada erlenmeyer de $25 \mathrm{~mL}$ (Figura 11(a)). A essas soluções foi adicionada a massa de nanoadsorvente (Figura 11(b)). Em seguida, os recipientes foram vedados (Figura 11(c)) e colocados em agitação orbital na Mesa Agitadora Orbital - AO-370 - Gehaka (Figura 11(d)), durante o tempo e a taxa de agitação estipulados para cada teste. 


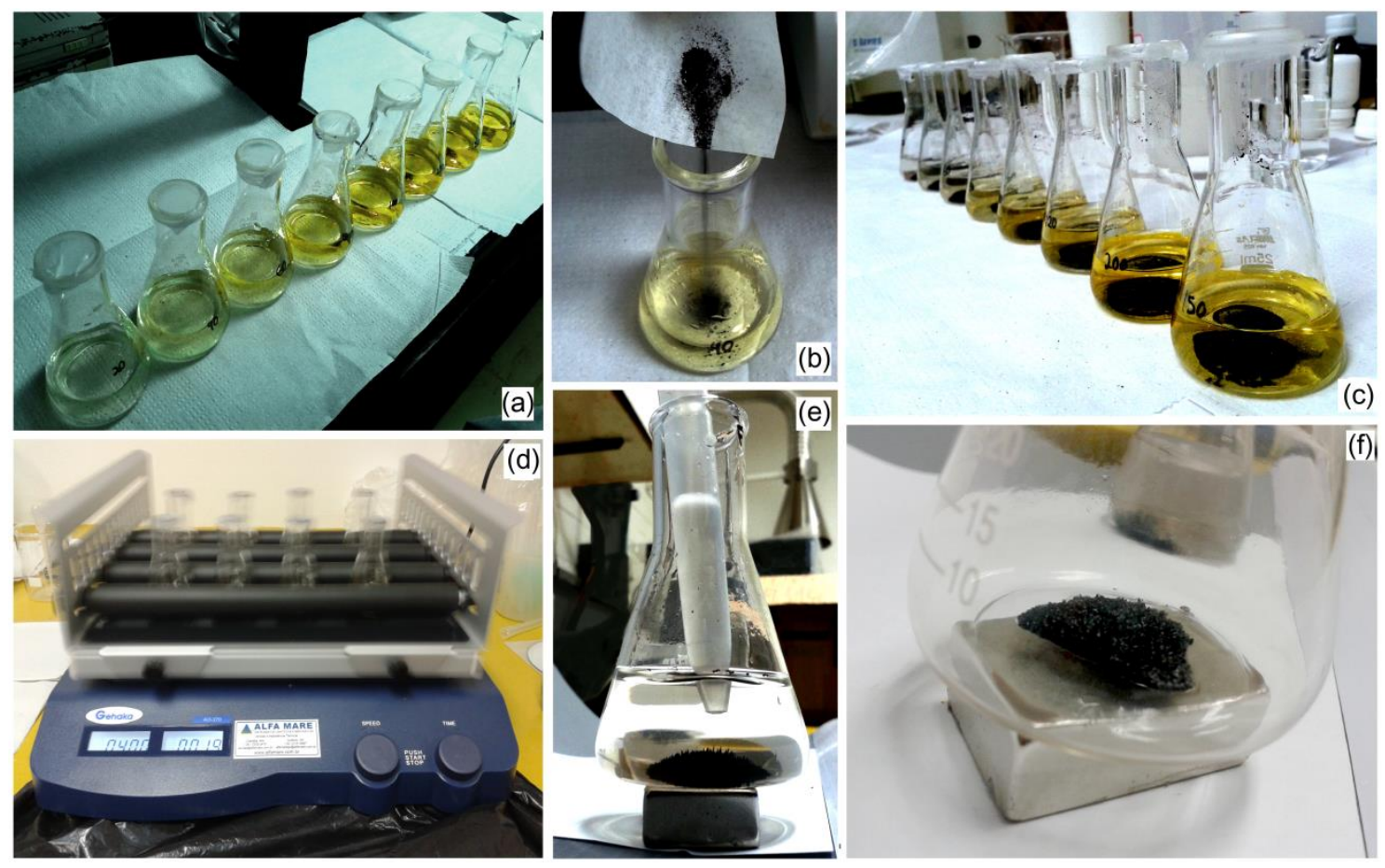

Figura 11: Fotos de etapas dos testes de adsorção. (a) bateria de amostras com concentração inicial e pH estabelecidos; (b) adição de nanoadsorventes à amostra; (c) recipientes vedados com os nanoadsorventes; (d) amostras sendo agitadas; (e) sobrenadante sendo retirado e (f) nanoadsorventes usados devidamente separados do sobrenadante.

Em seguida, cada erlenmeyer foi deixado em repouso sobre um ímã, durante aproximadamente 5 minutos, para assegurar que todo nanoadsorvente fosse sedimentado pela ação do ímã e da gravidade, promovendo a separação química do poluente. Nos primeiros segundos, todas as partículas visíveis do adsorvente já haviam se depositado na região mais próxima possível do ímã.

Com as nanopartículas sedimentadas, foi possível remover facilmente o sobrenadante com uma pipeta (Figura 11(e)), restando o precipitado dos nanoadsorventes que foram recolhidos para serem recuperados e reutilizados (Figura 11(f)) (Caítulo 4).

A concentração de cromo remanescente no sobrenadante foi determinada por espectroscopia de absorção atômica com chama (FAAS), que apresenta uma excelente precisão instrumental ${ }^{34,35}$. O espectrômetro utilizado foi o Thermo Scientific $S$ Series com chama de ar/acetileno e fluxo mantido em $1,6 \mathrm{~L} / \mathrm{min}$, altura do queimador em $12,6 \mathrm{~mm}$ e comprimento de onda de 357,9 nm (Figura 12), com análise em triplicata. 


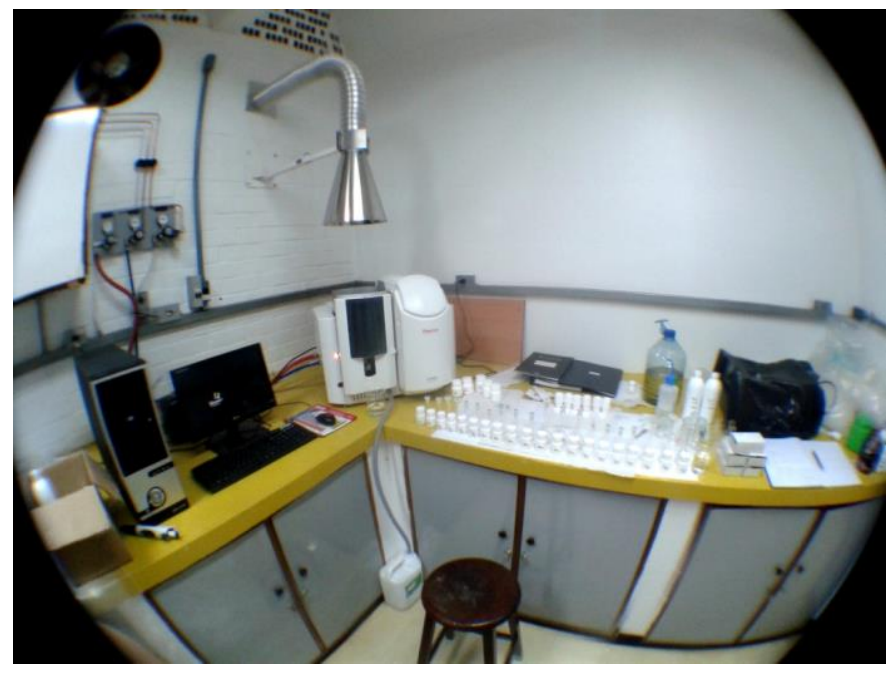

Figura 12: Sala do Espectrômetro de Absorção Atômica (AAS) no laboratório $3 \mathrm{Nano} / \mathrm{UnB}$.

A concentração de $\mathrm{Cr}(\mathrm{VI})$ adsorvida pelo nanomaterial $(\mathrm{mg} / \mathrm{L})$ foi calculada pela diferença da concetração de $\operatorname{Cr}(\mathrm{VI})$ inicial estabelecida e a concentração de $\operatorname{Cr}(\mathrm{VI})$ na fase sobrenadante. Já a quantidade de $\operatorname{Cr}(\mathrm{VI})$ adsorvida no equilíbrio $(\mathrm{mg} / \mathrm{g})$, para cada concentração inicial, foi calculada pela equação a seguir,

$$
q_{e}=\frac{\left(C_{0}-C_{e}\right) V}{m},
$$

em que $C_{0}$ é a concentração inicial de $\operatorname{Cr}(\mathrm{VI})(\mathrm{mg} / \mathrm{L}), C_{e}$ é a concentração do adsorvato em equilíbrio (mg/L), aferida após a adsorção. $V$ é o volume (L) da solução e $m$ é a massa ( $\mathrm{g}$ ) de nanoadsorvente utilizada para cada amostra. Finalmante, a taxa percentual de remoção de $\mathrm{Cr}(\mathrm{VI})$ pelo nanoadsorvente foi calculada como:

$$
\text { Taxa de remoção } \%=\frac{\left(C_{0}-C_{e}\right)}{C_{0}} \times 100 \% \text {. }
$$

Para confirmar que o $\mathrm{Cr}(\mathrm{VI})$ removido das soluções havia sido adsorvido pelo nanoadsorvente, foram feitas análises de espectroscopia de infravermelho com transformada de Fourrier (FTIR), com as nanopartículas antes e depois de elas serem utilizadas nas baterias de testes para remover o $\mathrm{Cr}(\mathrm{VI})$. Foi 
empregado o espectrofotômetro FT-IR PerkinElmer modelo Frontier com amostras dispersas em pastilhas de brometo de potássio (KBr).

A figura 13 mostra os espectros de FT-IR obtidos nos quais pode-se observar o pico em $585 \mathrm{~cm}^{-1}$, característico do estiramento $\mathrm{Fe}-\mathrm{O}$ dos sítios tetraédricos da ferrita espinélio ${ }^{30,31}$. Ainda, nas curvas obtidas com as nanopartículas após a realização dos testes de adsorção, o pico em $948 \mathrm{~cm}^{-1}$ pertence ao $\mathrm{CrO}_{4}^{2-36}$, indicando a capacidade adsorptiva de $\mathrm{Cr}(\mathrm{VI})$ dos nanomateriais sintetizados.
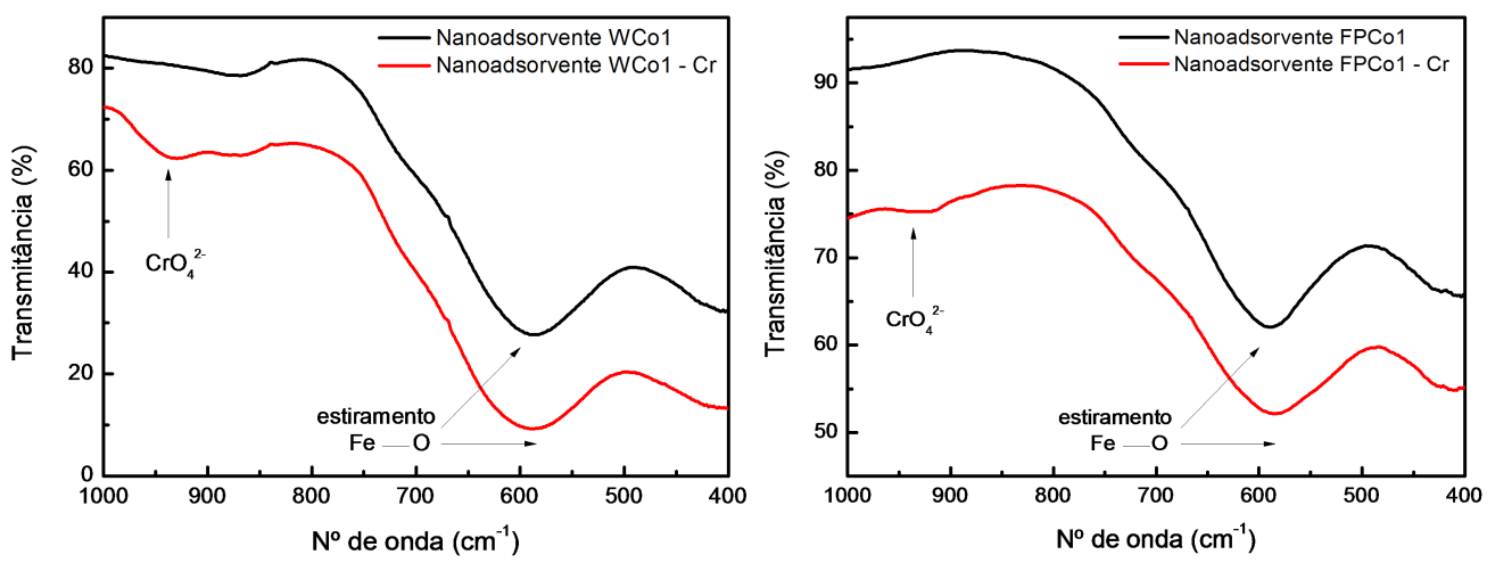

Figura 13: Resultado de FTIR para os dois nanoadsorventes estudados antes e depois das baterias de testes de adsorção.

Tendo em vista que a nanopartícula realmente adsorve o cromo, buscou-se neste trabalho encontrar as melhores condições para alcançar a maior adsorção possível, considerando a realidade aplicável na indústria.

Cada teste teve como objetivo analisar um parâmetro diferente importante para ocorrer a adsorção. A seguir, são apresentados esses parâmetros, sua importância, e como foram preparadas as baterias de amostras de cada teste e seus resultados.

\subsection{Influência do Tempo de Contato}

O estudo do tempo de contato foi feito para entender a cinética de adsorção de $\mathrm{Cr}(\mathrm{VI})$ pelos nanoadsorventes. Além disso, também foi verificada a 
influência da concentração inicial de $\mathrm{Cr}(\mathrm{VI})$ e do pH na adsorção no decorrer do tempo.

Para esse estudo foram feitos quatro testes para cada nanoadsorvente, com concentrações iniciais de $20 \mathrm{mg} / \mathrm{L}$ e de $50 \mathrm{mg} / \mathrm{L}$ de $\mathrm{Cr}(\mathrm{VI})$ e com $\mathrm{pHs}=2,5$ e 8,0, e taxa de agitação sempre em 400 RPM. As condições estabelecidas para cada teste estão listadas na Tabela 4.

\begin{tabular}{ccc}
\hline \hline Nanoadsorvente & $\mathbf{p H}$ & $\boldsymbol{C}_{\mathbf{0}}(\mathrm{mg} / \mathrm{L})$ \\
\hline \hline WCo1 & 2,5 & 20 \\
FPCo1 & 2,5 & 20 \\
WCo1 & 2,5 & 50 \\
FPCo1 & 2,5 & 50 \\
WCo1 & 8,0 & 20 \\
FPCo1 & 8,0 & 20 \\
WCo1 & 8,0 & 50 \\
FPCo1 & 8,0 & 50 \\
\hline \hline
\end{tabular}

Tabela 4: Condições fixadas para os oito testes para avaliar a influência do tempo de contado. Cada teste contou com 6 amostras variando o tempo de contato.

Cada teste contou uma bateria de 6 amostras, correspondentes aos tempos de contanto de $2,5,10,15,20$ e 25 minutos.

Ao final de cada tempo, os nanoadsorventes carregados com $\mathrm{Cr}(\mathrm{VI})$ foram separados com o auxílio de um ímã, e uma alíquota do sobrenadante foi coletada para determinar a concentração de $\mathrm{Cr}(\mathrm{VI})$ remanescente.

A figura 14 mostra a dependência da porcentagem de remoção de $\mathrm{Cr}(\mathrm{VI})$ com tempo de contato. Pode-se observar que quanto maior o tempo de contato das amostras, maior é a porcentagem removida de $\operatorname{Cr}(\mathrm{VI})$. Com $5 \mathrm{~min}$. de contato já se obtém a remoção máxima do $\mathrm{Cr}(\mathrm{VI})$ para o nanoadsorvente FPCo1 em pH = 2,5 e 8,0 a 20 mg/L. Observa-se também que levou um maior tempo de contato para se alcançar a remoção máxima nos testes com maiores concentrações iniciais, de $50 \mathrm{mg} / \mathrm{L}$, que atingiram 0 equilíbrio em aproximadamente 15 minutos de contato. Em maiores concentrações iniciais, a porcentagem de remoção foi menor, mas a quantidade adsorvida foi maior. Em todos os casos, a taxa de remoção nos primeiros minutos é muito alta, e com o passar do tempo vai diminuindo até estabilizar. Esse fenômeno pode ter ocorrido devido aos sítios na superfície do nanoadsorvente estarem 
extremamente disponíveis no princípio, e com o passar do tempo foram sendo ocupados ${ }^{24,37}$. Houve remoção de praticamente $100 \%$ do $\operatorname{Cr}(\mathrm{VI})$ das soluções com concentração inicial de $20 \mathrm{mg} / \mathrm{L}$, independentemente do $\mathrm{pH}$ e do nanoadsorvente, e também com o teste do FPCo1 em $50 \mathrm{mg} / \mathrm{L}$ de $\mathrm{Cr}(\mathrm{VI})$ inicial $\mathrm{apH}=2,5$.

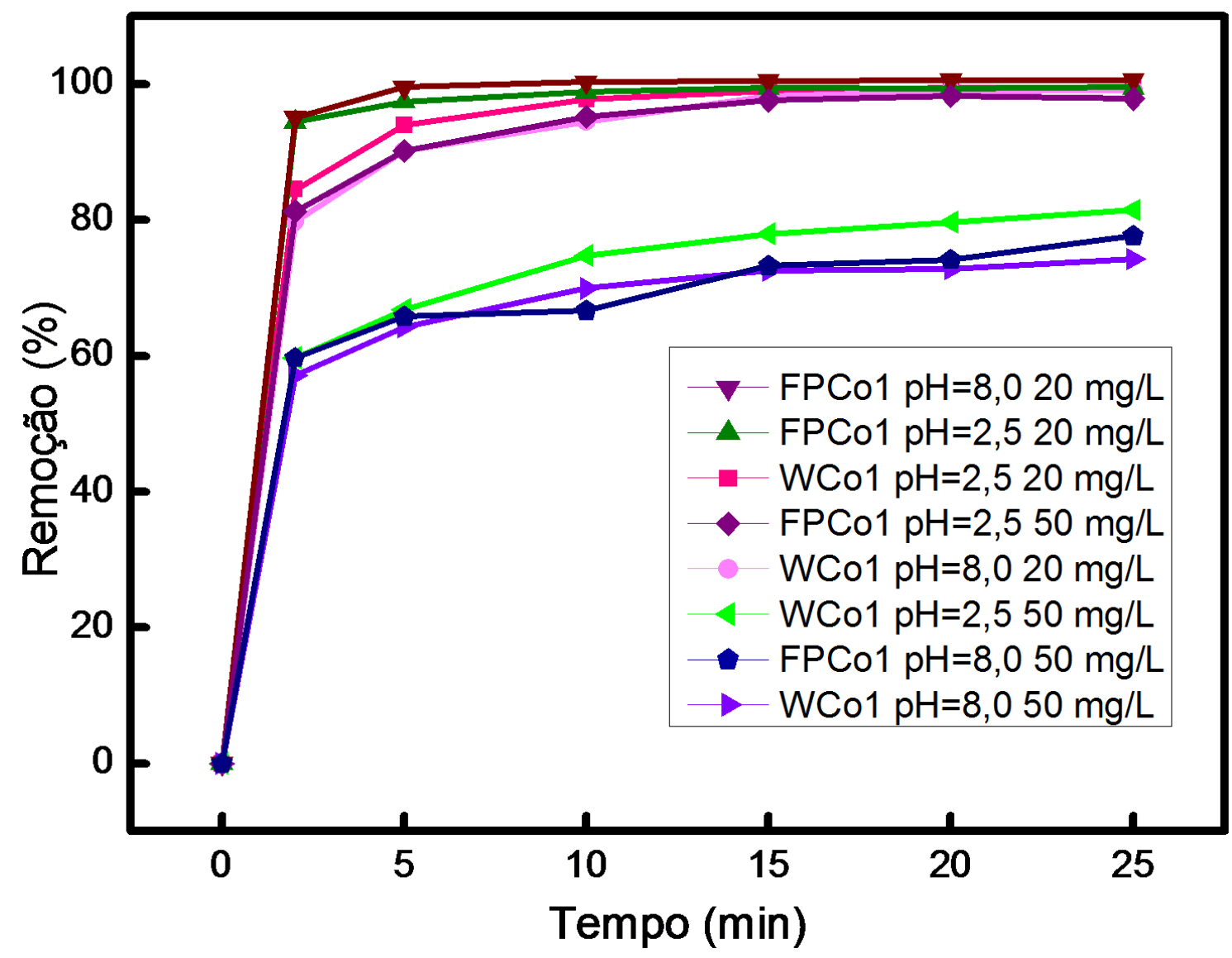

Figura 14: Porcentagem de remoção de $\mathrm{Cr}(\mathrm{VI})$ em função do tempo.

Nos testes com a concentração inicial de $20 \mathrm{mg} / \mathrm{L}$, a influência do pH não foi significativa no caso do nanoadsorvente FPCo1. Mas ao se observarem os testes com $50 \mathrm{mg} / \mathrm{L}$ de $\mathrm{Cr}(\mathrm{VI})$ iniciais, nota-se uma grande diferença. Os nanoadsorventes adsorveram aproximadamente $100 \% \circ \operatorname{Cr}(\mathrm{VI})$ das soluções de $20 \mathrm{mg} / \mathrm{L}$ iniciais, não sendo evidenciada a influência do $\mathrm{pH}$, que só ocorreu no teste com $50 \mathrm{mg} / \mathrm{L}$ de $\mathrm{Cr}(\mathrm{VI})$ iniciais, onde em $\mathrm{pH}=2,5$ houve maior adsorção (cerca de 100\%) do que em pH = 8 (cerca de 75\%) para o FPCo1. Com o WCo1 ocorreu algo parecido, mas com uma diferença bem menos discrepante, onde a remoção foi inferior ao FPCo1. A Tabela 5 lista os valores 
de porcentagem máxima de adsorção para os nanoadsorventes investigados, nas diferentes condições de concentração inicial de $\mathrm{Cr}(\mathrm{VI})$ e pH.

\begin{tabular}{ccccc}
\hline Nanoadsorvente & pH & $\boldsymbol{C}_{\mathbf{0}}(\mathrm{mg} / \mathrm{L})$ & $\begin{array}{c}\text { Remoção Máxima } \\
(\%)\end{array}$ & $\begin{array}{c}\text { Remoção Máxima } \\
(\mathbf{m g} / \mathbf{g})\end{array}$ \\
\hline WCo1 & 2,5 & 20 & 100,0 & 4,0 \\
FPCo1 & 2,5 & 20 & 100,0 & 4,0 \\
WCo1 & 2,5 & 50 & 81,5 & 8,2 \\
FPCo1 & 2,5 & 50 & 97,9 & 9,7 \\
WCo1 & 8,0 & 20 & 99,2 & 3,9 \\
FPCo1 & 8,0 & 20 & 100,0 & 4,0 \\
WCo1 & 8,0 & 50 & 74,2 & 7,4 \\
FPCo1 & 8,0 & 50 & 77,7 & 7,8 \\
\hline \hline
\end{tabular}

Tabela 5: Porcentagem e quantidade máxima de remoção de $\mathrm{Cr}(\mathrm{VI})$ em função da concentração inicial de poluente e do pH para os nanoadsorventes investigados.

A taxa em que ocorre a adsorção é um importante indicativo da eficiência de um adsorvente ${ }^{37}$. Para determinar essa taxa, utilizaram-se modelos de cinética de adsorção, que relacionam a quantidade de $\operatorname{Cr}(\mathrm{VI})$ adsorvida com o tempo decorrido e assim é possível prever a taxa em que ocorre uma reação. Os modelos também permitem identificar o mecanismo que controla o processo de adsorção.

Considere a adsorção e dessorção de um soluto $S$ em certa solução representadas por

$$
S_{(a q)}+* \frac{k_{a}}{\rightleftharpoons k_{d}} S_{(a)}
$$

em que $k_{a}$ e $k_{d}$ são as constantes da taxa de adsorção e dessorção, * representa o sítio de adsorção e $S_{(a)}$ o soluto adsorvido no sítio. As taxas de adsorção $v_{a}$ e dessorção $v_{d}$ são definidas como ${ }^{38}$

$$
\begin{gathered}
v_{a}=k_{a} C(1-\theta), \\
v_{d}=k_{d} \theta,
\end{gathered}
$$

em que $\theta$ é a fração de sítios ocupados $(0 \leq \theta \leq 1)$ e $C$ é a concentração molar de soluto em qualquer tempo. A equação da taxa global é ${ }^{38}$

$$
\begin{gathered}
\frac{d \theta}{d t}=v_{a}-v_{d}, \\
\frac{d \theta}{d t}=k_{a} C(1-\theta)-k_{d} \theta .
\end{gathered}
$$


A concentração do soluto na solução diminui enquanto ele é adsorvido na superfície do adsorvente ${ }^{38}$,

$$
C=C_{0}-\beta \theta,
$$

em que $C_{0}$ é a concentração inicial do soluto, $C$ é a concentração molar em qualquer tempo, $\theta$ é a fração da superfície coberta, e $\beta$ é ${ }^{38}$

$$
\beta=\frac{m_{c} q_{m}}{M_{w} V},
$$

em que $m_{c}$ é a massa ( $\mathrm{g}$ ) do adsorvente, $q_{m}$ é a capacidade máxima de adsorção do adsorvente $(\mathrm{mg} / \mathrm{g}), M_{w}$ é a massa molar do soluto $(\mathrm{g} / \mathrm{mol})$, e $V$ é o volume da solução (L). Pode-se reescrever $\beta \mathrm{como}^{38}$

$$
\beta=\frac{C_{0}-C_{e}}{\theta_{e}},
$$

em que $C_{e}$ é a concentração de equilíbrio do soluto e $\theta_{e}$ é a fração de sítios ocupados em equilíbrio ${ }^{38}$. Inserindo a eq. 13 na eq. 12 ,

$$
\frac{d \theta}{d t}=k_{a}\left(C_{0}-\beta \theta\right)(1-\theta)-k_{d} \theta .
$$

A equação 16 é a equação geral usada em diferentes condições para derivação de vários modelos de cinética de adsorção ${ }^{38}$.

Neste estudo, os resultados experimentais foram ajustados aos modelos de Pseudo Primeira-Ordem e Pseudo Segunda-Ordem, por serem modelos amplamente difundidos na literatura na descrição de sistemas de adsorção com particulados em solução ${ }^{39-43}$.

O modelo da cinética de Pseudo Primeira-Ordem é o modelo no qual a taxa da reação é diretamente proporcional à concentração do reagente. Isso acontece quando a concentração inicial de soluto é muito maior do que $\beta \theta$, e a eq. 16 pode ser resolvida ignorando-se o termo $\beta \theta^{38}$,

$$
\ln \frac{\left(q_{e}-q_{t}\right)}{q_{e}}=-k_{1} t .
$$

em que $q_{t}$ é a quantidade de soluto adsorvida $(\mathrm{mg} / \mathrm{g})$ no tempo $t(\mathrm{~min}), q_{e}$ é a quantidade de soluto adsorvida $(\mathrm{mg} / \mathrm{g})$ no equilíbrio e $k_{1}$ é a constante da reação de Pseudo Primeira-Ordem $\left((\mathrm{mg} \mathrm{min})^{-1}\right)$.

No caso em que a concentração inicial não é tão alta comparada ao número de sítions disponíveis no adsorvente, 0 termo $\beta \theta$ não pode ser desprezado e a forma integrada da equação 16 resulta em ${ }^{38}$ 


$$
\frac{1}{q_{t}}=\left(\frac{1}{k_{2} q_{e}^{2}}\right) \frac{1}{t}+\frac{1}{q_{e}},
$$

que corresponde ao modelo de cinética de Pseudo Segunda-Ordem ${ }^{14,44-49}$ em que $k_{2}$ é a constante da reação de Pseudo Segunda-Ordem ((mg min $\left.)^{-1}\right)$.

Dessa forma, a cinética de adsorção de adosrvatos em soluções líquidas costuma ser mais bem descrita pelo modelo de Pseudo Segunda-Ordem a baixas concentrações iniciais de adsorvatos, enquanto que para concentrações iniciais maiores, ajusta-se melhor ao modelo de Pseudo Primeira-Ordem ${ }^{38}$. Esse foi justamente o resultado obtido neste trabalho. Para o ajuste foi utilizado o programa Origin.

Como se pode verificar na Tabela 6, para concentrações de $\operatorname{Cr}(\mathrm{VI})$ de $20 \mathrm{mg} / \mathrm{L}$ o modelo de Pseudo Segunda-Ordem mostrou coeficientes de correlação $\left(R^{2}\right)$ bastante altos. Para a concentração inicial de $\operatorname{Cr}(\mathrm{VI})$ de $50 \mathrm{mg} / \mathrm{L}$ esses valores de $\mathrm{R}^{2}$ diminuíram enquanto que os referentes ao modelo de Pseudo Primeira-Ordem aumentaram significativamente. Para a condição de 50 ppm e pH = 8,0, a cinética do processo de adsorção se ajustou melhor ao modelo de Pseudo Primeira-Ordem, mostrando que, nessas condições, a quantidade sítios ativos à adsorção no nanoadsorvente é pequena comparada à quantidade de $\mathrm{Cr}(\mathrm{VI})$ na solução.

\begin{tabular}{ccccc}
\hline \hline Nanoadsorvente & $\mathbf{p H}$ & $\boldsymbol{C}_{\mathbf{0}}(\mathbf{m g} / \mathbf{L})$ & $\begin{array}{c}\mathbf{R}^{\mathbf{2}} \text { Pseudo } \\
\text { Primeira-Ordem }\end{array}$ & $\begin{array}{c}\mathbf{R}^{\mathbf{2}} \text { Pseudo } \\
\text { Segunda-Ordem }\end{array}$ \\
\hline \hline WCo1 & 2,5 & 20 & 0,538 & 0,998 \\
FPCo1 & 2,5 & 20 & 0,578 & 0,994 \\
FPCo1 & 8,0 & 20 & 0,396 & 0,970 \\
WCo1 & 8,0 & 20 & 0,668 & 0,987 \\
FPCo1 & 2,5 & 50 & 0,627 & 0,988 \\
WCo1 & 8,0 & 50 & 0,729 & 0,965 \\
WCo1 & 2,5 & 50 & 0,808 & 0,924 \\
FPCo1 & 8,0 & 50 & 0,905 & 0,787 \\
\hline \hline
\end{tabular}

Tabela 6: Valores de Coeficiente de Correlação $\left(R^{2}\right)$ obtidos pelo ajuste dos resultados cinéticos com os modelos de Pseudo Primeira-Ordem e Pseudo Segunda-Ordem para cada teste.

Para as condições gerais investigadas neste trabalho, o modelo que melhor se ajustou ao comportamento cinético foi o de Pseudo Segunda-Ordem, em concordância com outros estudos similares ${ }^{15,42,50}$. Para Anirudhan e colaborador $^{51}$, isso indica que a etapa determinante da cinética de adsorção 
envolve forças de valência por meio de troca ou compartilhamento de elétrons entre o adsorvente e o adsorvato ${ }^{51,52}$.

Dessa forma, para se investigar quantitativamente o processo de adsorção, os resultados do estudo de tempo de contato foram ajustados com o modelo de Pseudo Segunda-Ordem (figura 15) e os parâmetros cinéticos obtidos pela equação 18 (Tabela 7).

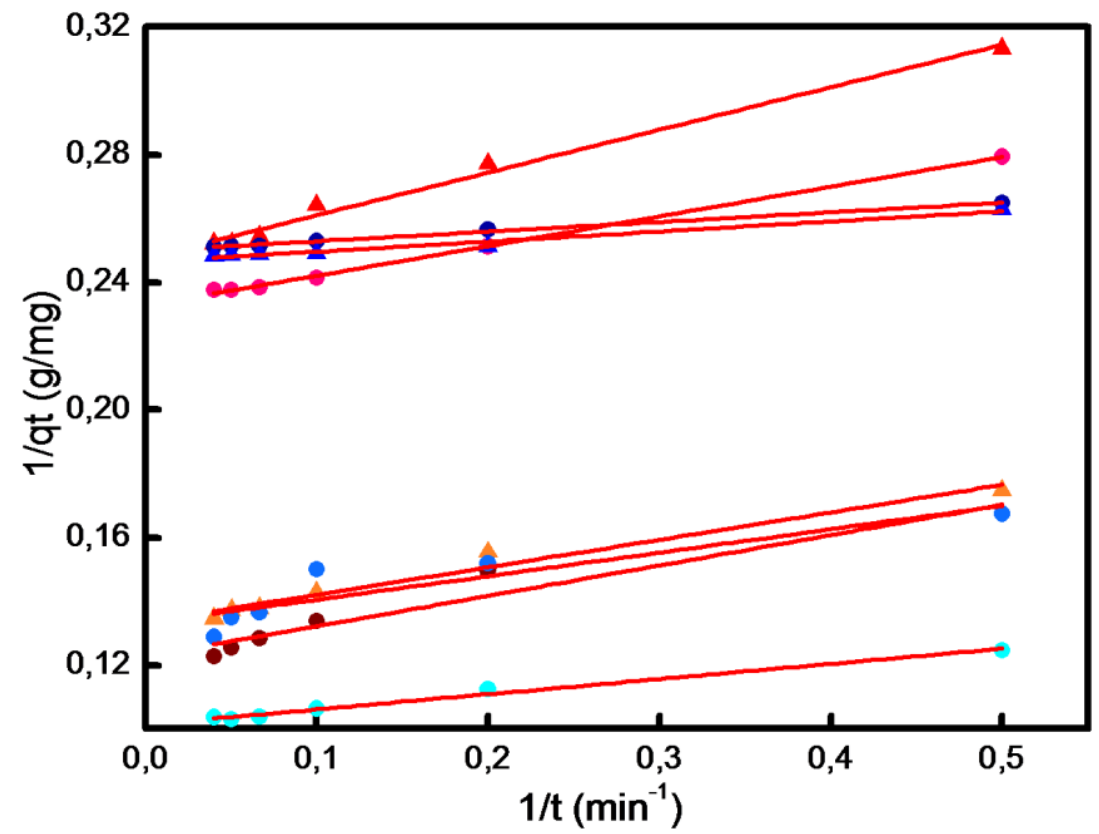

A FPCo1 $-\mathrm{pH}=8,0-20 \mathrm{mg} / \mathrm{L}$

- FPCo1 $-\mathrm{pH}=2,5-20 \mathrm{mg} / \mathrm{L}$

- $W$ Co $1-\mathrm{pH}=2,5-20 \mathrm{mg} / \mathrm{L}$

- FPCo1 $-\mathrm{pH}=2,5-50 \mathrm{mg} / \mathrm{L}$

$\triangle W C o 1-\mathrm{pH}=8,0-20 \mathrm{mg} / \mathrm{L}$

- $W C o 1-\mathrm{pH}=2,5-50 \mathrm{mg} / \mathrm{L}$

- FPCo1 $-\mathrm{pH}=8,0-50 \mathrm{mg} / \mathrm{L}$

$\triangle W C o 1-\mathrm{pH}=8,0-50 \mathrm{mg} / \mathrm{L}$

Figura 15: Ajuste dos resultados com o modelo de cinética de Pseudo SegundaOrdem.

\begin{tabular}{ccccc}
\hline \hline Nanoadsorvente & $\mathbf{p H}$ & $\boldsymbol{C}_{\mathbf{0}}(\mathbf{m g} / \mathbf{L})$ & $\boldsymbol{k}_{\mathbf{2}}(\mathbf{g} / \mathbf{m i n} \mathbf{~ m L})$ & $\boldsymbol{q}_{\boldsymbol{e}}(\mathbf{m g} / \mathbf{g})$ \\
\hline \hline FPCo1 & 2,5 & 20 & 2,06 & 4,00 \\
FPCo1 & 8,0 & 20 & 1,92 & 4,06 \\
WCo1 & 2,5 & 20 & 0,58 & 4,35 \\
WCo1 & 8,0 & 20 & 0,46 & 3,99 \\
FPCo1 & 8,0 & 50 & 0,24 & 7,51 \\
FPCo1 & 2,5 & 50 & 0,22 & 9,86 \\
WCo1 & 8,0 & 50 & 0,21 & 7,49 \\
WCo1 & 2,5 & 50 & 0,16 & 8,15 \\
\hline \hline
\end{tabular}

Tabela 7: Parâmetros do modelo de pseudo segunda-ordem para cada teste.

O valor da constante $k_{2}$ foi significativamente maior para os testes com $C_{0}=20 \mathrm{mg} / \mathrm{L}$ do que para os feitos com $C_{0}=50 \mathrm{mg} / \mathrm{L}$. Esse comportamento pode ser explicado devido à energia de ligação envolvida no processo de 
adsorção do $\operatorname{Cr}(\mathrm{VI})^{41}$. Para uma mesma massa de nanoadsorvente, se a concentração de adsorvato for pequena, haverá um número maior de sítios de mais alta energia de adsorção disponíveis, e o processo ocorrerá mais rapidamente ${ }^{41}$. Para concentrações de adsorvato mais elevadas, a maior parte dos sítios de alta energia de adsorção já estarão ocupados de modo que a adsorção ocorrerá então mais lentamente ${ }^{41}$. É importante destacar que esses fenômenos ocorrem em casos em que a adsorção é do tipo física, onde não há adsorção específica. Pang e colaboradores ${ }^{50}$ afirmam que é comum o valor da constante $k_{2}$ diminuir com 0 aumento da concentração inicial, visto que a quantidade de adsorvente é fixa, o que significa que os sítios de adsorção são limitados. Resultados com baixos valores da constante $k_{2}$ e grandes valores de concentração inicial indicam adsorção em multicamadas.

As concentrações iniciais (20 e $50 \mathrm{mg} / \mathrm{L}$ ) influenciaram de forma considerável a taxa de adsorção. O segundo fator que mais influenciou foi o tamanho médio do nanoadsorvente. O nanoadsorvente FPCo1 removeu $\mathrm{Cr}(\mathrm{VI})$ mais rapidamente do que o WCo1, apesar de a diferença ter sido pouco significativa com os testes em $C_{0}=50 \mathrm{mg} / \mathrm{L}$. Nessa condição também não houve diferença significativa no valor da constante $k_{2}$ alterando-se o pH. Ela só pôde ser observada nos testes a $C_{0}=20 \mathrm{mg} / \mathrm{L}$, que mostraram maior valor da constante $k_{2}$ nos testes em $\mathrm{pH}=2,5$. Apesar de 0 valor da constante de velocidade não sofrer alterações significativas a $C_{0}=50 \mathrm{mg} / \mathrm{L}$ com a mudança de $\mathrm{pH}$, houve diferença no valor de $q_{e}$ : maior quantidade de $\operatorname{Cr}(\mathrm{VI})$ foi adsorvida nos testes em $\mathrm{pH}=2,5$. A influência do $\mathrm{pH}$ será explorada no tópico 4 desse capítulo.

\subsection{Influência da Concentração Inicial de $\operatorname{Cr}(\mathrm{VI})$}

O estudo da influência da concentração inicial de cromo teve como objetivo determinar a natureza e a capacidade de adsorção dos nanoadsorventes.

$\mathrm{Na}$ busca de entender o tipo de adsorção que ocorre entre o $\mathrm{Cr}(\mathrm{VI})$ e o nanoadsorvente, ajustaram-se os resultados obtidos dos testes com isotermas 
de adsorção. Uma isoterma de adsorção descreve a dependência entre a quantidade de adsorvato adsorvida e a concentração da solução em equilíbrio. Foram escolhidas as isotermas dos modelos de Langmuir e de Freundlich.

Para utilizar o modelo da isoterma de Langmuir, considera-se que 0 adsorvente possui uma superfície homogênea, que contém sítios que o adsorvato ocupará15,53. A adsorção é específica e as forças que a regem são semelhantes as que atuam em uma reação. Todos os sítios são considerados equivalentes e possuem a mesma energia de ligação com o adsorvato, independentemente da ocupação ou não dos sítios vizinhos. As moléculas ou íons metálicos do adsorvato estariam continuamente colidindo com 0 adsorvente e ao colidir com um sítio livre, ocorreria a ocupação desse sítio. Uma monocamada ocorre quando todos os sítios estão preenchidos, e não pode haver mais ligações.

O modelo de Langmuir é descrito pela equação:

$$
q_{e}=\frac{K_{L} q_{m a ́ x} C_{e}}{1+K_{L} C_{e}}
$$

em que $K_{L}$, é a constante de Langmuir, relacionada a energia de ligação (L/mg), e $q_{m a ́ x}$, é a capacidade máxima de adsorção do adsorvente (mg/g).

A isoterma de Freundlich se ajusta bem em situações em que a superfície do adsorvente é heterogênea, permitindo a formação de multicamadas ${ }^{15}$ com adsorção física. Na adsorção física, ou fisiossorção, o adsorvato interage eletrostaticamente com o adsorvente, mediado por forças de van der Waals. Ela é rápida, reversível e não específica. A equação correspondente à isoterma de Freundlich é:

$$
q_{e}=K_{F} C_{e}^{1 / n}
$$

em que $K_{F}$ é a constante de Freundlich $(\mathrm{mg} / \mathrm{g})$, relacionada com a capacidade adsorção e $n$, é o fator de heterogeneidade do adsorvente, que reflete a intensidade da adsorção. Valores elevados de $K_{F}$ indicam maior capacidade de adsorção. No caso do fator de heterogeneidade ${ }^{13,15,41}$ :

- $\quad$ se $n<1 \Rightarrow$ adsorção fraca;

- se $1<n<2 \Rightarrow$ adsorção moderadamente difícil; e

- $\quad$ se $2<n<10 \Rightarrow$ adsorção favorável. 
Para o estudo da influência da concentração inicial de $\mathrm{Cr}(\mathrm{VI})$ na capacidade de adsorção dos nanomateriais investigados, foram realizadas baterias de testes com soluções padronizadas de $\mathrm{Cr}(\mathrm{VI})$ nas seguintes concentrações: $20,40,60,80,100,120,150$ e $200 \mathrm{mg} / \mathrm{L}$, em pH =2,5, com agitação em 400 RPM durante 20 minutos. A figura 16 mostra os resultados obtidos, ajustados pelos modelos de Langmuir e de Freundlich. Na Tabela 8 estão listados os parâmetros extraídos de cada modelo.

\begin{tabular}{cccc}
\hline \hline Isoterma & Parâmetro & WCo1 & FPCo1 \\
\hline \hline \multirow{3}{*}{ Langmuir } & $K_{L}(\mathrm{~L} / \mathrm{mg})$ & 0,41 & 1,00 \\
& $q_{\text {máx }}(\mathrm{mg} / \mathrm{g})$ & 11,33 & 15,34 \\
& $\mathrm{R}^{2}$ & 0,83 & 0,80 \\
\multirow{3}{*}{ Freundlich } & $K_{F}(\mathrm{mg} / \mathrm{g})$ & 5,17 & 7,63 \\
& $n$ & 5,56 & 5,59 \\
& $\mathrm{R}^{2}$ & 0,95 & 0,96 \\
\hline \hline
\end{tabular}

Tabela 8: Parâmetros obtidos de cada Isoterma.

Em todos os ajustes, os valores das constantes $K_{L}$ e $K_{F}$ foram maiores para o nanoadsorvenete FPCo1 do que para $\circ \mathrm{WCo1}$, indicando que a capacidade de remoção de $\mathrm{Cr}(\mathrm{VI})$ é maior com FPCo1. Esse resultado é confirmado com o parâmetro $q_{\text {máx }}$, a capacidade máxima de adsorção estimada pela equação de Langmuir, que foi de $11,33 \mathrm{mg} / \mathrm{g}$ para WCo1 e $15,34 \mathrm{mg} / \mathrm{g}$ para FPCo1. O valor de $n$ obtido na equação de Freundlich foi da ordem de 5 , indicando que a adsorção do $\operatorname{Cr}(\mathrm{VI})$ é um processo favorável para os dois nanoadsorventes.

$O$ valores baixos de $R^{2}$ da ordem de 0,8 no ajuste com Langmuir revela que a adsorção de $\operatorname{Cr}(\mathrm{VI})$ não ocorre em monocamada. Por outro lado, os valores do coeficiente de correlação foram elevados para o modelo de Freundlich, indicando que a superfície da partícula é heterogênea e que a adsorção é de natureza física. 

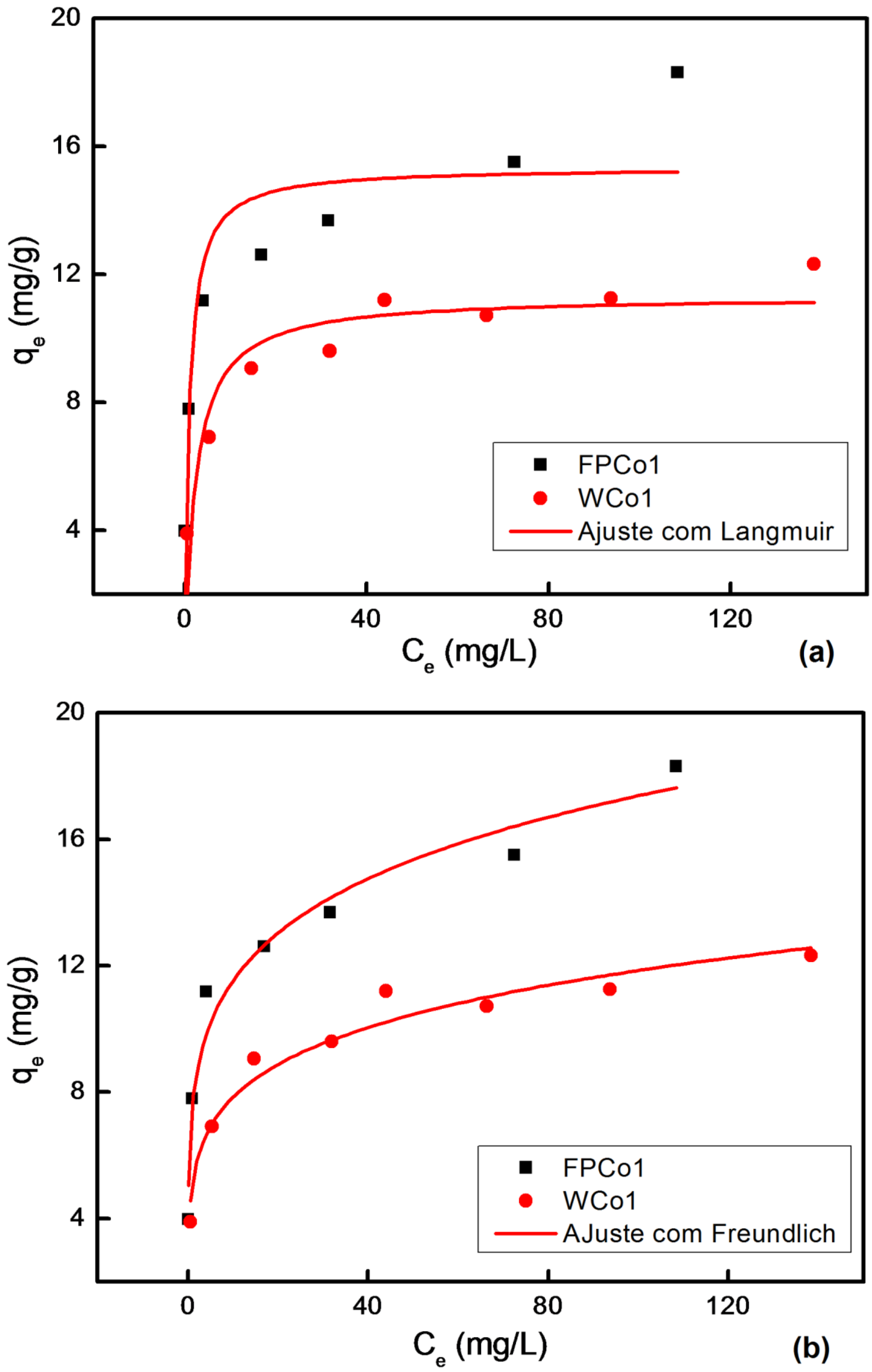

Figura 16: Ajuste dos resultados com as Isotermas de Langmuir (a) e Freundlich (b). 


\subsection{Influência do pH do Meio}

$\mathrm{O}$ cromo hexavalente especia-se em solução aquosa em função do $\mathrm{pH}$ do meio, como se pode verificar na figura $17^{54}$.

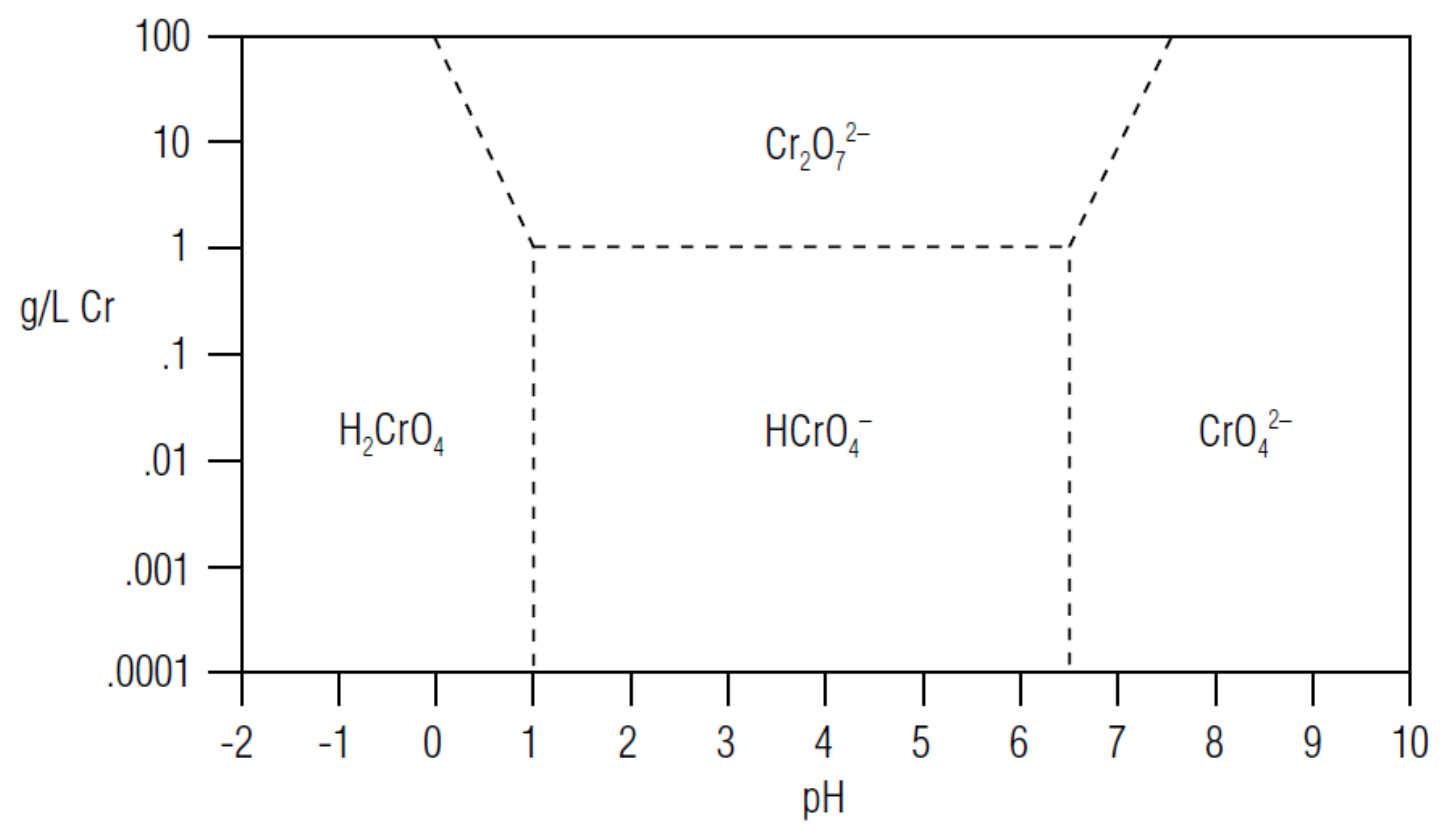

Figura 17: Diagrama de especiação do $\mathrm{Cr}(\mathrm{VI})$ em diferentes concentrações e $\mathrm{pHs}^{54}$.

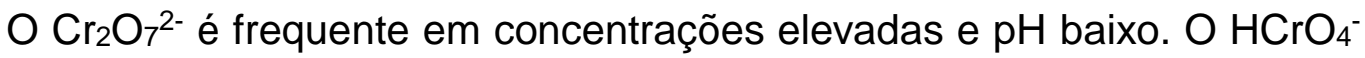
ocorre em $\mathrm{pH}$ baixo e em concentrações de $\mathrm{Cr}(\mathrm{VI})$ abaixo de $1 \mathrm{~g} / \mathrm{L}$. Em elevados valores de $\mathrm{pH} \circ \mathrm{CrO}_{4}{ }^{2-}$ é a forma predomindante ${ }^{15,20}$. Portanto, as espécies de $\mathrm{Cr}(\mathrm{VI})$ dominantes no intervalo de $\mathrm{pH}$ estudado nos processos de adsorção são $\mathrm{HCrO}_{4}^{-}(1<\mathrm{pH}<6,5)$ e $\mathrm{CrO}_{4}^{2-}(\mathrm{pH}>6,5)$.

Além de alterar a especiação do $\mathrm{Cr}(\mathrm{VI})$, o pH altera também a superfície do adsorvente (Figura 18), que, por apresentar comportamento ácido-base, pode se tornar carregada positiva ou negativamente, ou mesmo eletricamente neutra (ponto de carga nula - PCN, pH onde a carga dos sítios superficiais é nula), de acordo com os equilíbrios:

$$
\begin{array}{cl}
\equiv & \mathrm{FeOH}+\mathrm{H}_{3} \mathrm{O}^{+} \rightleftharpoons \equiv \mathrm{FeOH}_{2}+\mathrm{H}_{2} \mathrm{O} \\
\equiv \mathrm{FeOH}+\mathrm{OH}^{-} \rightleftharpoons \equiv \mathrm{FeO}^{-}+\mathrm{H}_{2} \mathrm{O}, & \text { eq. } 21
\end{array}
$$


em que $\equiv \mathrm{FeOH}, \equiv \mathrm{FeOH}_{2}{ }^{+}$e $\equiv \mathrm{FeO}^{-}$correspondem aos sítios superficiais neutros, positivos e negativos, respectivamente. Dessa forma, para valores de $\mathrm{pH}>\mathrm{PCN}$, a superfície se tornará carregada negativamente, enquanto que para valor de $\mathrm{pH}<\mathrm{PCN}$, a superfície ficará positivamente carregada. Assim, como o $\mathrm{Cr}(\mathrm{VI})$ se apresenta na forma de ânion, e a superfície do adsorvente fica positivamente carregada com o decréscimo do $\mathrm{pH}$, a adsorção do $\operatorname{Cr}(\mathrm{VI})$ será favorável a baixos valores de $\mathrm{pH}$ (Figura 18)46,55. É importante evidenciar que o PCN para esses tipos de nanopartículas é da ordem de 7,056.

O diagrama da figura 18 estima a proporção de espécies que ocorrem em diferentes valores de $\mathrm{pH}$, tanto do $\operatorname{Cr}(\mathrm{VI})$ quanto da superfície do nanoadsorvente. A faixa prevista de adsorção ótima indicada ocorre entre os pHs 1 e 5. Nesta faixa, a superfície do nanoadsorvente permanece acima de $50 \%$ carregada positivamente enquanto $\circ \mathrm{Cr}(\mathrm{VI})$ está predominantemente monoaniônico $\left(\mathrm{HCrO}_{4}{ }^{-}\right)$. A atração eletrostática entre $\mathrm{o} \quad \mathrm{Cr}(\mathrm{VI})$ carregado negativamente e a superfície do nanoadsorvente positivamente carregada permitem a adsorção ser favorável nessa faixa de $\mathrm{pH}$.

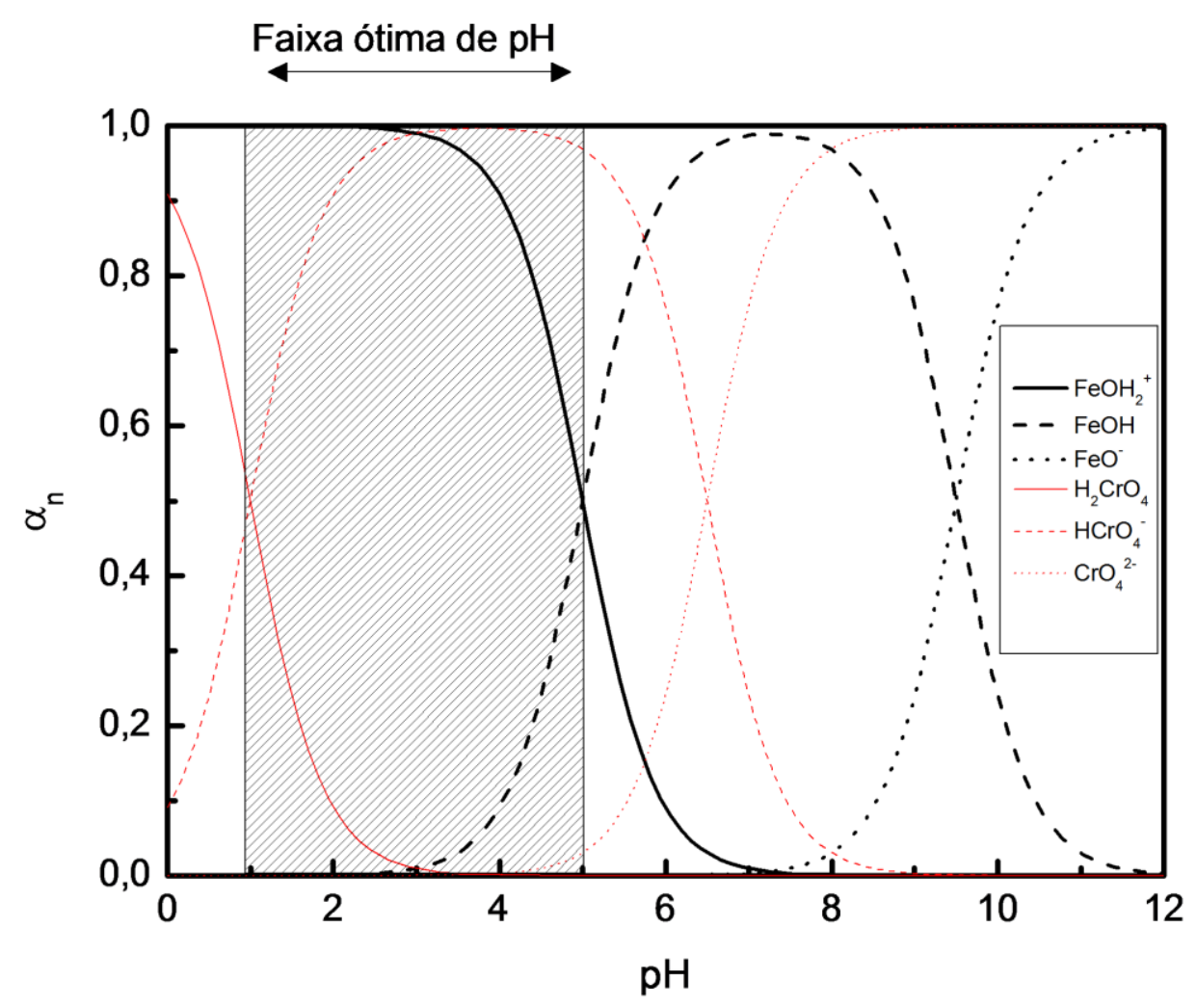

Figura 18: Diagrama representativo das espécies ocorrentes de $\mathrm{Cr}(\mathrm{VI})(\mathrm{em}$ vermelho) e da superfície do nanoadsorvente (em preto) em meios aquosos por $\mathrm{pH}$. 
Para investigar diretamente a influência do $\mathrm{pH}$ do meio na adsorção foram feitos testes com 4 amostras para cada nanoadsorvente. A faixa de $\mathrm{pH}$ estudada foi de 2,5 até 10 .

As condições fixas para cada teste foram:

- Teste 1: nanoadsorvente WCo1, $C_{0}=50 \mathrm{mg} / \mathrm{L}, 20 \mathrm{~min} ., 400 \mathrm{RPM}$;

- Teste 2: nanoadsorvente FPCo1, $C_{0}=80 \mathrm{mg} / \mathrm{L}, 20 \mathrm{~min}$., $400 \mathrm{RPM}$;

Cada teste contou com quatro amostras distinguidas pelos valores de $\mathrm{pH}$, aproximadamente iguais a 2,5, 5, 8 e 10. A figura 19 apresenta a porcentagem de $\mathrm{Cr}(\mathrm{VI})$ removida em cada um dos testes, para os dois nanoadsorventes.
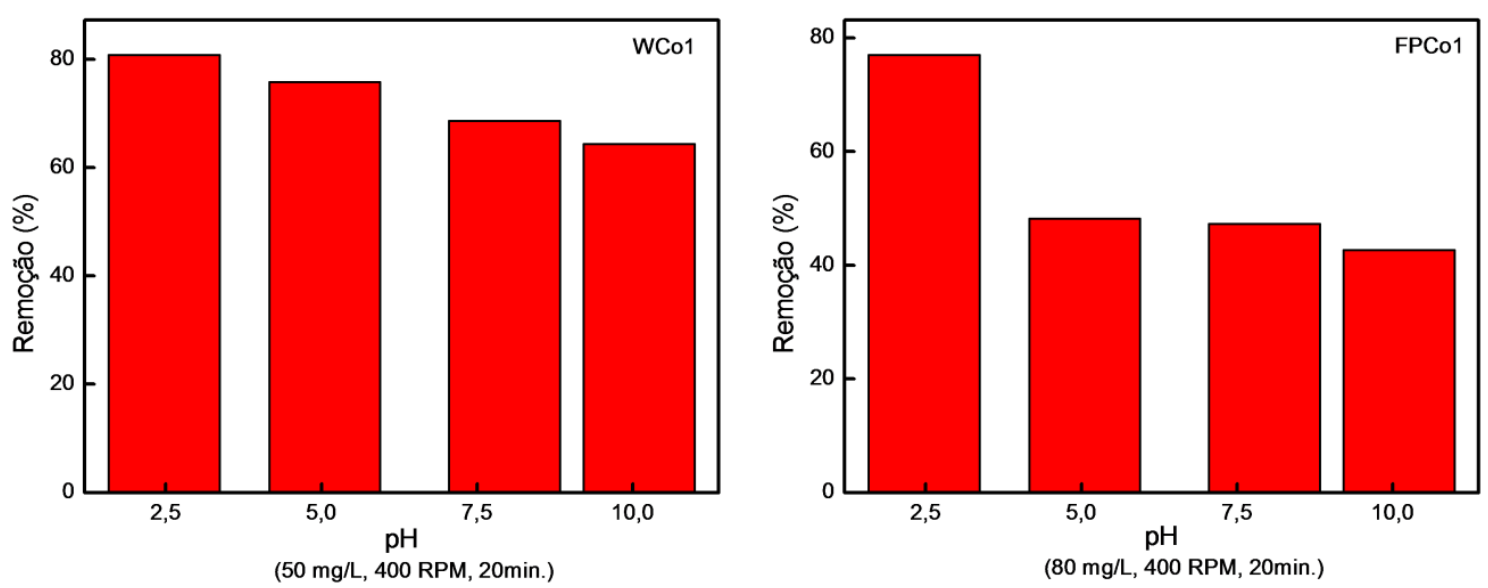

Figura 19: Porcentagens de remoção de $\mathrm{Cr}(\mathrm{VI})$ pelo pH da solução.

Em ambos os testes, a porcentagem de remoção aumentou com a diminuição do $\mathrm{pH}$, como era esperado, devido à interação eletrostática entre a a superfície do nanoadsorvente carregada positivamente $\left(\equiv \mathrm{FeOH}_{2}{ }^{+}\right)$e 0 adsorvato carregado negativamente (figura 20(a)). A remoção máxima foi em $\mathrm{pH}=2,5$. Mas também houve remoção em valores de $\mathrm{pH}$ acima de 2,5, o que pode significar que exista um outro tipo de interação entre o nanoadsorvente e - $\mathrm{Cr}(\mathrm{VI})$, que seja menos relevante do que o mecanismo de interação eletrostática. Uma hipótese é que haja uma ligação de coordenação entre o ferro e o cromato, esquematizada na figura $20(b)$, em que seja 
energeticamente vantajosa a substituição da hidroxila pelo cromato, a valores de $\mathrm{pH}$ elevados ${ }^{24}$.

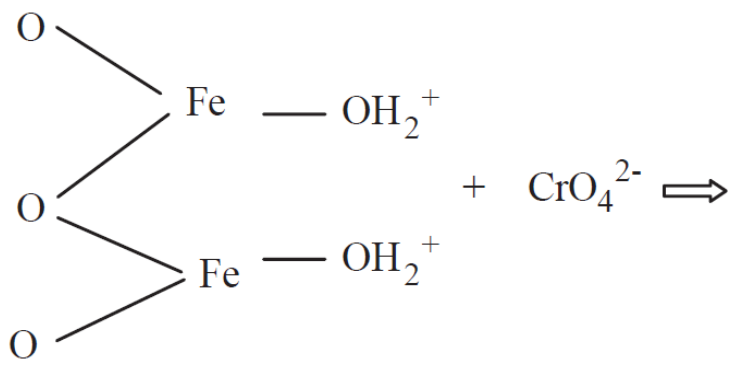

$\mathrm{O}$

$\mathrm{O}$

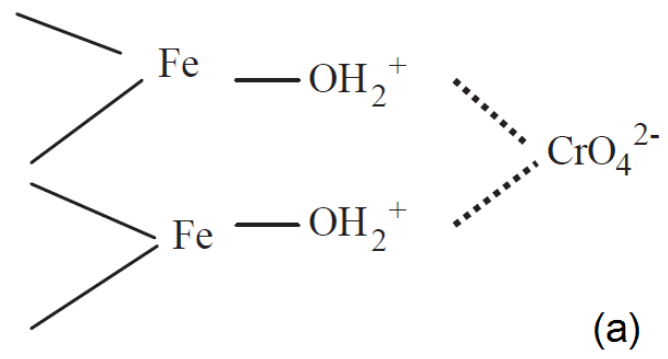

Fe

$-\mathrm{OH}$

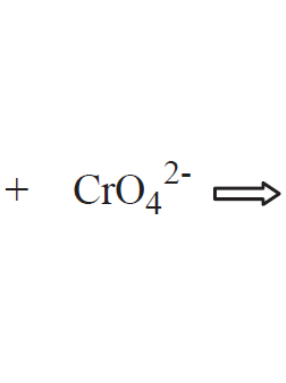

$\mathrm{O}$<smiles>C[I+]1CC1(F)F</smiles><smiles>CC(C)[Po+]</smiles>

$\mathrm{O}$

(b)

Figura 20: Esquema de possível interação entre a superfície do nanoadsorvente e o meio carregado positivamente (a) e negativamente (b) ${ }^{24}$.

\subsection{Influência da Taxa de Agitação}

A interação entre os íons e os sítios de adsorção do adsorvente na solução pode ser maximizada pela taxa de agitação 20 .

Para avaliar o quanto a taxa da agitação da solução interfere na adsorção do $\mathrm{Cr}(\mathrm{VI})$, foram preparadas 4 amostras padronizadas de $\mathrm{Cr}(\mathrm{VI})$ nas seguintes condições:

- Nanoadsorvente WCo1, $C_{0}=20 \mathrm{mg} / \mathrm{L}, 20 \mathrm{~min} ., \mathrm{pH}=2,5$.

As 4 amostras se diferenciaram pela taxa de agitação em que cada uma foi agitada. As taxas foram 100, 200, 300 e 400 RPM. A figura 21 apresenta a porcentagem de remoção de cada uma das amostras. 


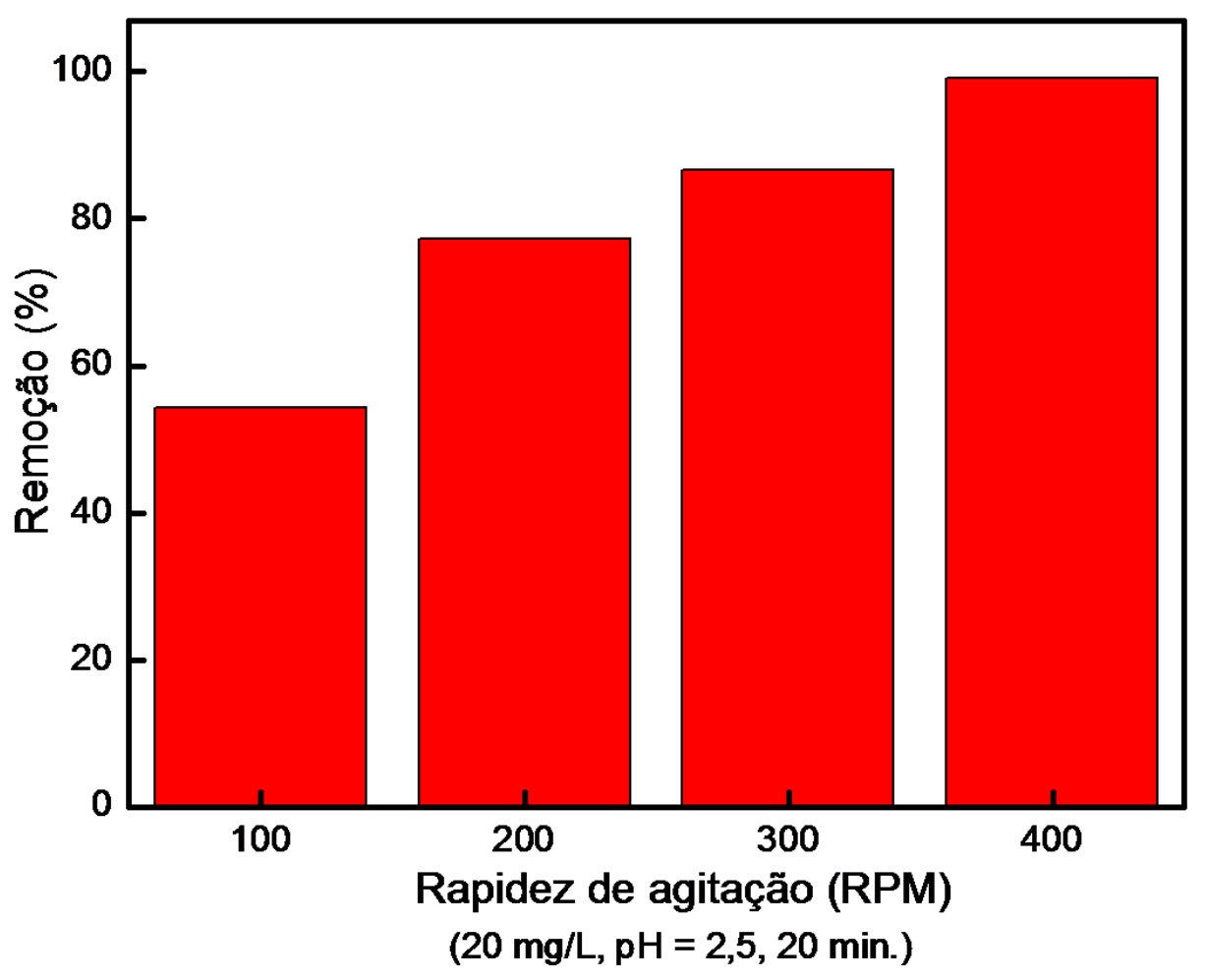

Figura 21: Influência da taxa de agitação na remoção de $\mathrm{Cr}(\mathrm{VI})$.

Quanto maior a taxa de agitação, maior é a porcentagem de remoção de $\mathrm{Cr}(\mathrm{VI})$. A taxa de agitação está diretamente relacionada à quantidade de sítios expostos para ocorrer adsorção. $O$ aumento da taxa de agitação permite 0 sistema ficar mais homogeneizado, com os nanoadsorventes mais dispersos,

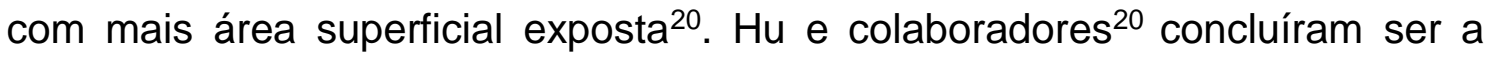
taxa de 400 RPM a mais eficiente para adsorção de $\mathrm{Cr}(\mathrm{VI})$ em diversos tipos de ferrita. Para partículas com propriedades magnéticas é necessária maior agitação mecânica para vencer a força magnética natural entre elas ${ }^{20}$.

\subsection{Estimação de Parâmetros Termodinâmicos à Temperatura Ambiente}

Neste trabalho, todos os estudos de adsorção foram realizados sob temperatura ambiente de $25^{\circ} \mathrm{C}(T=298 \mathrm{~K} \pm 2)$. Os parâmetros termodinâmicos podem ser estimados a partir da constante termodinâmica de equilíbrio $K_{0}$, 
também denominada coeficiente termodinâmico de distribuição, que pode ser definida como:

$$
K_{0}=\frac{a_{s}}{a_{e}}=\frac{v_{s} C_{s}}{v_{e} C_{e}},
$$

em que $a_{s}$ é a atividade do $\operatorname{Cr}(\mathrm{VI})$ adsorvido, $a_{e}$ é a atividade do $\operatorname{Cr}(\mathrm{VI})$ em solução no equilíbrio, $v_{s}$ é o coeficiente de atividade do $\operatorname{Cr}(\mathrm{VI})$ adsorvido, $v_{e}$ é o coeficiente de atividade do $\operatorname{Cr}(\mathrm{VI})$ em solução no equilíbrio e $C_{S}$ é a concentração do $\operatorname{Cr}(\mathrm{VI})$ adsorvido no nanoadsorvente. No caso limite, quando as concentrações de $\mathrm{Cr}(\mathrm{VI})$ adsorvido e em solução aproximam-se de zero, os coeficientes de atividade tendem à unidade, de modo que a equação anterior pode ser escrita como ${ }^{57,58}$ :

$$
\lim _{C_{s} \rightarrow 0} \frac{a_{s}}{a_{e}}=\frac{C_{s}}{C_{e}}=K_{0} .
$$

Dessa forma, $K_{0}$ pode ser determinado plotando-se a curva de $\left(C_{s} / C_{e}\right)$ em função de $C_{s}$ (Figura 22), com o programa Origin, e extrapolando-se o valor de $C_{s}$ para zero ${ }^{41}$. O intercepto da curva por ajuste dos pontos experimentais corresponde à $K_{0}$.
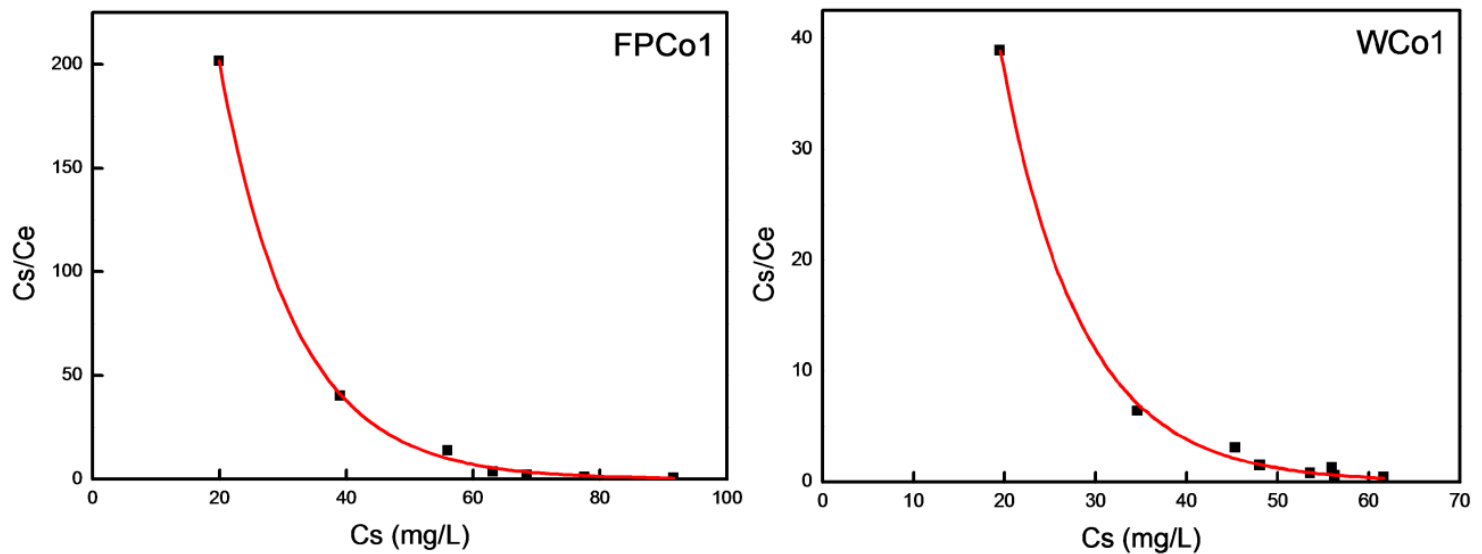

Figura 22: Curvas $\left(C_{s} / C_{e}\right)$ em função de $C_{s}$ para os dois nanoadsorventes estudados. 
Os valores da variação de energia livre de Gibbs no equilíbrio $\left(\Delta G^{9}\right)$ foram, então, calculados pela equação de van't Hoff ${ }^{59}$ :

$$
\Delta G^{0}=-R T \ln K_{0},
$$

em que $R$ é a constante dos gases ideais e $T$ é a temperatura absoluta. A Tabela 9 lista os valores de $K_{0}$ e $\Delta G^{0}$ obtidos, em $\mathrm{pH}=2,5$ e taxa de agitação de 400 RPM.

Os valores negativos de $\Delta G^{0}$ indicam que a adsorção ocorre espontaneamente. Ainda, os módulos de $\Delta G^{0}$ são inferiores a $20 \mathrm{~kJ} / \mathrm{mol}$, valores típicos de processos de adsorção física ${ }^{59}$, o que confirma hipótese anteriormente discutida. Finalmente, os valores mais elevados de $K_{0}$ e $\left|\Delta G^{0}\right|$ para o FPCo1 relevam, mais uma vez, que a capacidade de adsorção de cromo é mais favorável com esse nanoadsorvente.

\section{Parâmetro FPC01 WCo1 $K_{0} \quad 1057,3 \quad 351,7$} $\Delta G^{0}(\mathrm{~kJ} / \mathrm{mol}) \quad-17,3 \quad-14,6$

Tabela 9: Parâmetros termodinâmicos do processo de adsorção estimados sob temperatura ambiente. 


\section{Capítulo 4 - Recuperação e Reutilização dos Nanoadsorventes}

\subsection{Apresentação}

A grande vantagem de se utilizar nanoadsorventes magnéticos para remoção de metais de meios aquosos é a facilidade em removê-los da solução após a adsorção, com o auxílio de um campo magnético externo. Como existe essa facilidade de recolher o adsorvente, ele pode ser tratado para que haja uma dessorção do metal adsorvido para que não somente o nanoadsorvente possa ser reutilizado, mas também o metal dessorvido recuperado.

Considerando que o principal mecanismo de adsorção é a interação eletrostática, e que a adsorção é um processo físico reversível, é possível a regeneração do nanoadsorvente ${ }^{20}$. Assim a dessorção foi feita utilizando-se solução de $\mathrm{NaOH}$, eluente com maior potencial de dessorção do $\mathrm{Cr}(\mathrm{VI})$ da maguemita testado por Hu e colaboradores ${ }^{24}$.

O teste de recuperação do nanoadsorvente teve como objetivo avaliar a capacidade de reutilização do nanoadsorvente usado. O teste foi feito em duas etapas. A primeira etapa foi a dessorção. A segunda etapa foi o teste de reuso, em que foram feitas duas baterias de amostras alterando-se a concentração inicial, para determinar a capacidade de adsorção dos nanoadsorventes após a sua recuperação.

Para garantir que as partículas utilizadas neste teste de dessorção do $\mathrm{Cr}(\mathrm{VI})$ estavam saturadas com $\mathrm{Cr}(\mathrm{VI})$, elas foram agitadas durante $30 \mathrm{~min}$. com solução de $\mathrm{Cr}(\mathrm{VI})$ a $1000 \mathrm{mg} / \mathrm{L}$ em pH = 2,5 antes dos testes. Esse estudo foi conduzido com os dois tipos de nanoadsorventes elaborados neste trabalho.

\subsection{Recuperação dos Nanoadsorventes}

Para que ocorresse a dessorção do $\mathrm{Cr}(\mathrm{VI})$, uma solução de $\mathrm{NaOH}$ a $0,01 \mathrm{~mol} / \mathrm{L}$ foi deixada em contato com o nanoadsorvente com $\mathrm{Cr}(\mathrm{VI})$ por 30 
min. a 400 RPM. A amostra ficou bem escura, sinalizando que o $\mathrm{Cr}(\mathrm{VI})$ havia se dispersado na solução (Figura 22). Em seguida, a amostra foi deixada em repouso sobre um ímã até que o nanoadsorvente fosse coagulado no fundo. $O$ sobrenadante foi então recolhido. Esse procedimento foi repetido três vezes, sendo que ao final de cada ciclo, uma pequena porção de nanoadsorvente foi coletada, lavada com água deionizada tipo I duas vezes e seca, para medidas de fluorescência de raios $\mathrm{X}$ por dispersão de energia (EDX).

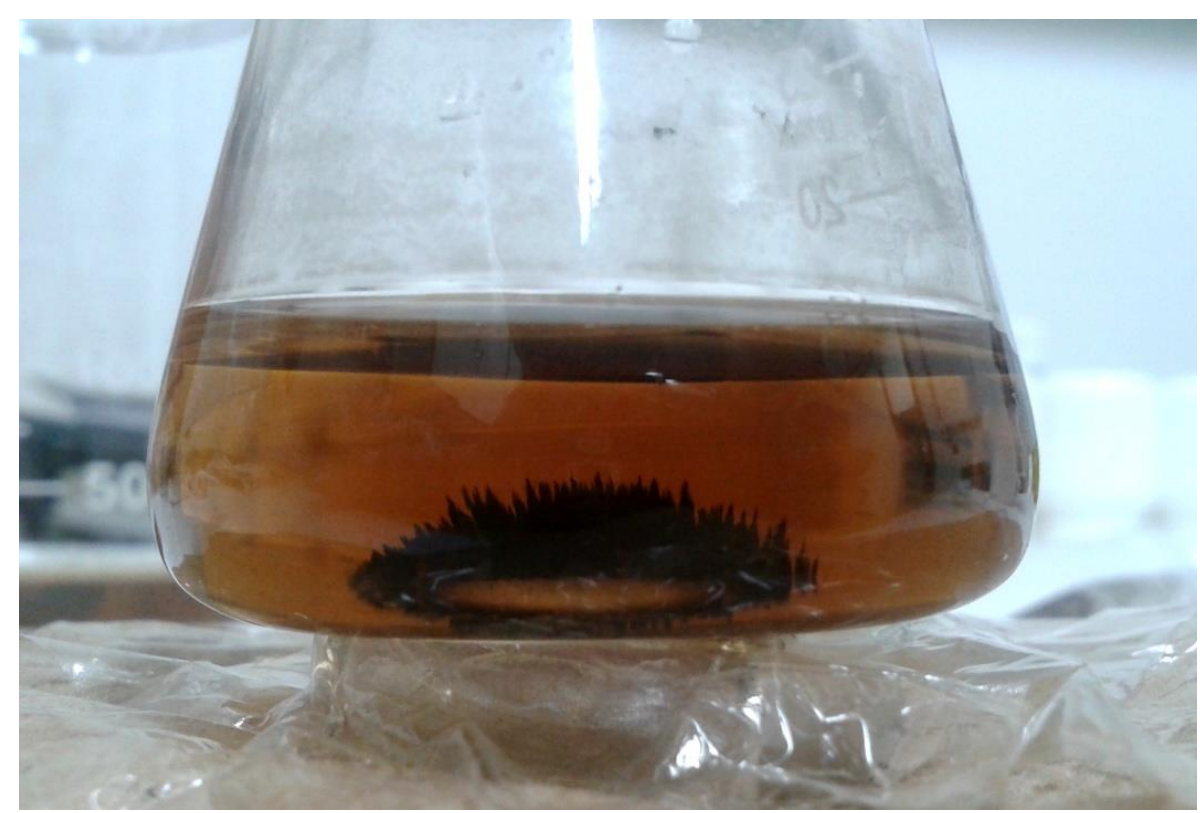

Figura 23: Dessorção do $\mathrm{Cr}(\mathrm{VI})$. A solução que inicialmente estava transparente, após a agitação, ficou escurecida. Isso ocorreu em cada ciclo. A cor resultante é proveniente do $\mathrm{Cr}(\mathrm{VI})$ dessorvido dos nanoadsorventes.

Os resultados das análises de EDX evidenciaram a proporção entre as quantidades de $\mathrm{Cr}$, Fe e Co presentes em cada amostra. Comparando-se os valores das proporções referentes a cada ciclo, pôde-se determinar a porcentagem de $\mathrm{Cr}(\mathrm{VI})$ liberada a cada ciclo, e assim, a porcentagem relativa de recuperação dos nanoadsorventes (Figura 23). 


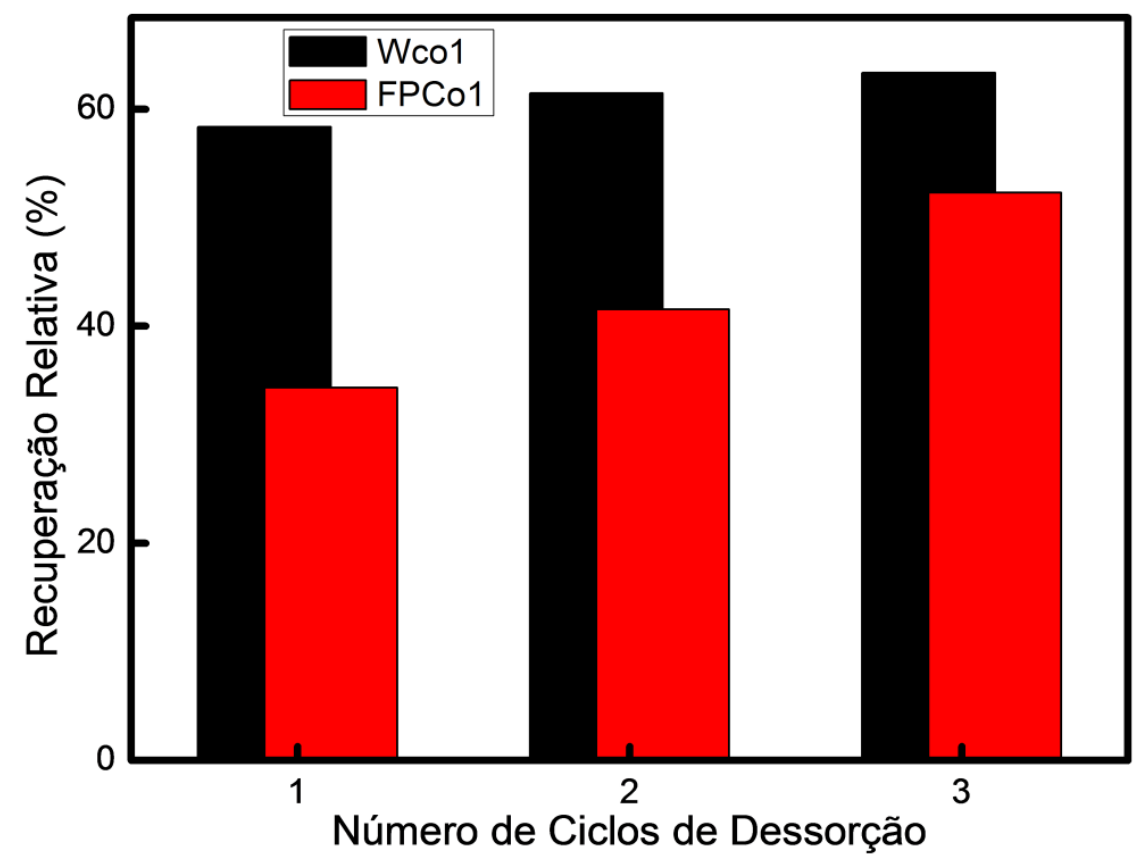

Figura 24: Recuperação relativa dos nanoadsorventes a cada ciclo de dessorção.

A recuperação dos nanoadsorventes $\mathrm{com} \mathrm{NaOH}$ foi de no máximo 63,35\% para o WCo1 e 52,34\% para o FPCo1 em 3 ciclos. Para o WCo1, o número de ciclos efetuados não influenciou significativamente a taxa de recuperação, diferentemente da amostra FPCo1. Verificou-se que seriam necessários mais ciclos com o FPCo1 para que fosse dessorvido mais $\operatorname{Cr}(\mathrm{VI})$, tendo em vista que ele adsorve mais $\mathrm{Cr}(\mathrm{VI})$ do que o WCo1.

A porcentagem de remoção relativa teve um valor mediano. Existe a possibilidade de estar ocorrendo outro mecanismo de adsorção, a troca iônica, discutida no item anterior (Influência do $\mathrm{pH}$ ). Se a afinidade do $\mathrm{CrO}_{4}{ }^{2-} \mathrm{com}$ a superfície do nanoadsorvente é maior que com o OH,$\circ \mathrm{CrO}_{4}{ }^{2-}$ pode substituir $\mathrm{OH}^{-}$da superfície da partícula ${ }^{24}$. É possível que haja uma camada significativa de adsorvato ligado que não foi dessorvido (cerca de $30 \%$ ou $40 \%$ ), e na dessorção só foi dessorvido o adsorvato que interagia eletrostaticamente. Outro fator que pode ter influenciado na baixa dessorção foi o tipo de agente dessorvedor. 


\subsection{Reutilização dos Nanoadsorventes}

Com as nanopartículas que passaram pelos três ciclos de dessorção, foram preparadas duas novas baterias de amostras, uma para cada nanoadsorvente, variando a concentração inicial, idêntica a descrita anteriormente (Capítulo 3.3), para avaliar a nova capacidade de adsorção dos nanoadsorventes. A figura 24 apresenta uma comparação entre a remoção de $\mathrm{Cr}(\mathrm{VI})$ com o nanoadsorvente original (em preto) e o nanoadsorvente recuperado (em vermelho).
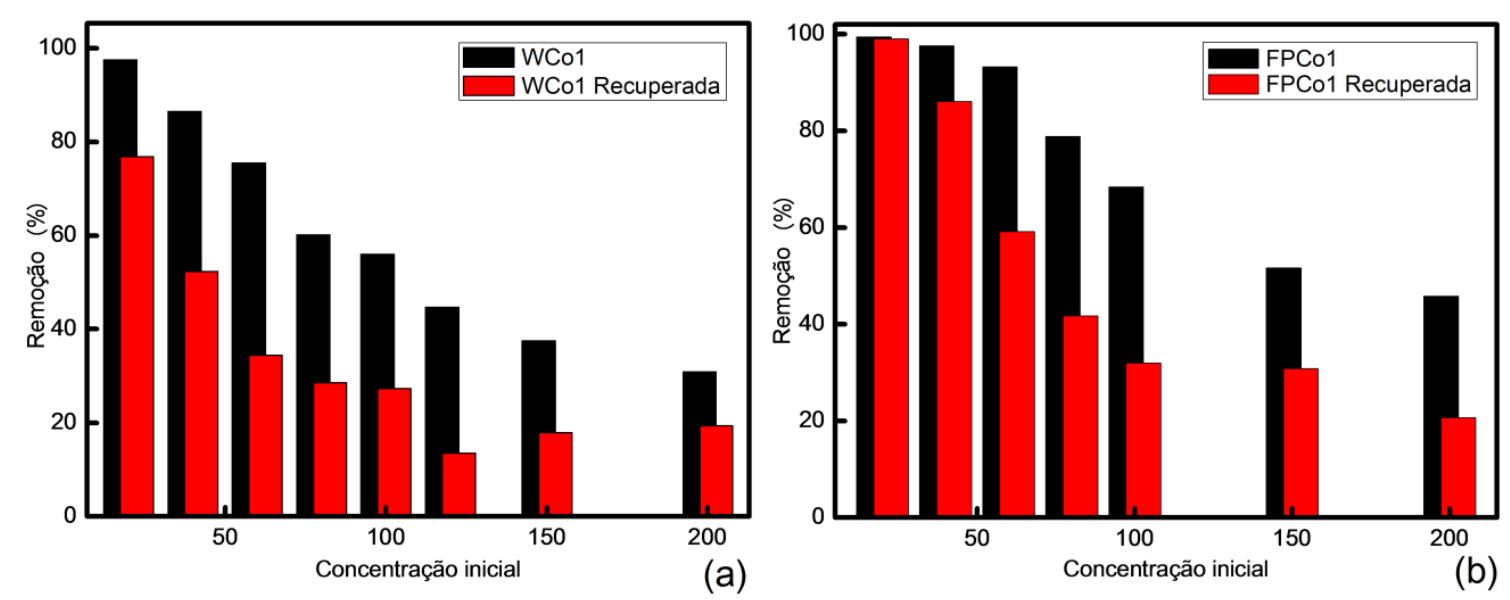

Figura 25: Comparação entre a porcentagem de remoção de $\mathrm{Cr}(\mathrm{VI})$ de cada nanoadsorvente antes e depois da recuperação.

Apesar do FPCo1 recuperado ter tido uma menor recuperação, ainda assim ele removeu mais que o WCo1 recuperado. Para a concentração inicial de $20 \mathrm{mg} / \mathrm{L}$ a remoção foi praticamente a mesma com o FPCo1 original e recuperado. Isso significa que o FPCo1 pode ser reutilizado em soluções onde a concentração inicial de $\mathrm{Cr}(\mathrm{VI})$ seja de $20 \mathrm{mg} / \mathrm{L}$. Sem dúvida, outras técnicas de recuperação ainda precisam ser investigadas ou desenvolvidas para aumentar a eficiência do processo e permitir o reuso dos nanoadsorventes em quaisquer condições físico-químicas. 


\section{Conclusão e Propostas Futuras}

Os nanoadsorventes baseados em nanopartículas do tipo core-shell, com núcleo de ferrita de cobalto e superfície de maguemita foram sintetizadas com sucesso em dois tamanhos médios, 7,2 e 13,8 nm, rotuladas como FPCo1 e WCo1, respectivamente. A polidispersão em tamanho teve um valor satisfatório, da ordem de 0,3.

A partir dos ensaios de adsorção propostos, verificou-se que o $\mathrm{Cr}(\mathrm{VI})$ foi eficientemente removido de soluções aquosas pelos nanoadsorventes elaborados. A eficiência de remoção foi maior com taxa de agitação orbital de 400 RPM. O valor do $\mathrm{pH}$ do meio influenciou consideravelmente o processo de adsorção, sendo o $\mathrm{pH}=2,5$ o de maior eficiência.

A cinética de adsorção foi adequadamente modelada pelo modelo de Pseudo Segunda-Ordem. A constante de taxa de adsorção e a capacidade de adsorção no equilíbrio dependem da concentração inicial, da taxa de agitação e do tamanho do nanoadsorvente. Quanto maior a concentração inicial de $\operatorname{Cr}(\mathrm{VI})$ maior a quantidade adsorvida e menor a taxa de adsorção.

O modelo de isoterma de adsorção que melhor se ajustou foi o de Freundlich, implicando adsorção física e de multicamada. $O$ fator de heterogeneidade apontou adsorção favorável. O Modelo de Langmuir, apesar de não ter se ajustado eficientemente, forneceu uma estimativa de capacidade de adsorção dos nanoadsorventes, igual a 11,33 e 15,34 mg/g para o WCo1 e FPCo1 respectivamente. A maior capacidade de adsorção do FPCo1 está associada à sua maior área superficial disponível, comparada a do WCo1, o que é uma marca dos materiais estruturados em nanoescala. No futuro podem ser mensuradas as áreas superficiais dos nanoadsorventes pela Teoria de Adsorção Multimolecular para maior exatidão na análise dos resultados.

Parâmetros termodinâmicos de adsorção foram estimados sob temperatura ambiente. Os valores de variação de energia livre calculados revelaram que o processo de adsorção é espontâneo e característico de adsorção física.

No balanço entre as propriedades magnéticas e a capacidade de adsorção dos nanoadsorventes, as propriedades magnéticas se mostraram 
pouco importantes no processo, importando muito mais a área superficial dos nanoadsorventes. A maior susceptibilidade magnética do WCo1 pode ter impedido que as partículas ficassem dispersas em contato com a solução, devido à interação dipolar magnética.

O custo e a performance dos adsorventes são relativamente vantajosos. Um quilograma de FPCo1 custa aproximadamente o mesmo que as maguemitas $(20-40 \mathrm{~nm})$ de Chowdhury e Yanful ${ }^{21}$, em torno de $\$ 225$, porém com uma capacidade de adsorção de $2,4 \mathrm{mg} / \mathrm{g}$, em $\mathrm{pH} \approx 2,0$, valor bem menor que a dos nanoadsorventes elaborados.

Os nanoadsorventes investigados são de fácil preparo, possuem baixo custo, e têm boa capacidade de adsorção, características de um material promissor para remoção de $\mathrm{Cr}(\mathrm{VI})$ de águas residuárias.

Uma proposta futura de estudo é a investigação do processo de adsorção em função da temperatura, que permitirá obter valores mais acurados de parâmetros termodinâmicos como não somente variação de energia livre, mas também variação de entalpia e variação de entropia.

O presente trabalho abre perspectivas importantes de estudos futuros para a adsorção de outros metais perigosos, além da influência de íons competitivos na adsorção, visto que em efluentes industriais podem existir outras substâncias em solução com o $\mathrm{Cr}(\mathrm{VI})$.

Finalmante, este estudo logrou sucesso no desenvolvimento de nanotecnologias ambientais com possibilidade de aplicação para poluentes orgânicos, a partir da funcionalização das nanopartículas com ligantes específicos.

\section{Referências Bibliográficas}

1. Callister, W. D. Ciência e Engenharia de Materiais: Uma Introdução. 2a. Edição.

2. Quina, F. H. Nanotecnologia e o meio ambiente: perspectivas e riscos.

Quim. Nov. 27, 1028-1029 (2004). 
3. Benetti, A. \& Bidone, F. in Hidrol. - Ciência e Apl. (Tucci, C. E. M.) 849875 (UFRGS Editora, 2007).

4. Dąbrowski, A. Adsorption - from theory to practice. Adv. Colloid Interface Sci. 93, 135-224 (2001).

5. Granados-Correa, F. \& Serrano-Gomez, J. Removal of Chromium Hexavalent Ions from Aqueous Solution by Retention onto Iron Phosphate. J. Chil. Chem. Soc. 55, 312-316 (2010).

6. Espinoza-Quiñones, F. R. et al. Inhibition effect on the Allium cepa L. root growth when using hexavalent chromium-doped river waters. Bull. Environ. Contam. Toxicol. 82, 767-71 (2009).

7. Digital, B. \& Centro, D. CONSTITUIÇÃO DA REPÚBLICA FEDERATIVA DO BRASIL 32. Edição 2010. (2010).

8. República, P. da, Civil, C. \& Jurídicos, S. para A. LEI No 9.433, DE 8 DE JANEIRO DE 1997. (1997). at <http://www.planalto.gov.br/ccivil_03/LEIS/L9433.htm>

9. RESOLUÇÃO № 357, DE 17 DE MARÇO DE 2005 Publicada no DOU nº 053, de 18/03/2005, págs. 58-63. (2011). at <http://www.mma.gov.br/port/conama/res/res05/res35705.pdf>

10. RESOLUÇÃO NN 430, DE 13 DE MAIO DE 2011. (2011). at <http://www.mma.gov.br/port/conama/res/res11/res43011.pdf>

11. Indústria. Anuário do $D F$ at <http://www.anuariododf.com.br/economia/industria/>

12. Aguiar, M. R. M. P. de, Novaes, A. C. \& Guarino, A. W. S. Remoção de metais pesados de efluentes industriais por aluminossilicatos. Quim. Nova 25, 1145-1154 (2002).

13. Lazaridis, N. K., Bakoyannakis, D. N. \& Deliyanni, E. a. Chromium(VI) sorptive removal from aqueous solutions by nanocrystalline akagan??ite. Chemosphere 58, 65-73 (2005).

14. Thinh, N. N. et al. Magnetic chitosan nanoparticles for removal of $\mathrm{Cr}(\mathrm{VI})$ from aqueous solution. Mater. Sci. Eng. C 33, 1214-1218 (2013).

15. Jiang, W. et al. Chromium(VI) removal by maghemite nanoparticles. Chem. Eng. J. 222, 527-533 (2013).

16. Silva, C. S. \& Pedrozo, M. D. F. M. Ecotoxicologia do cromo e seus compostos. (2001). 
17. Colombo. Determinação de $\mathrm{CROMO}+6.5-6$

18. Matos, W. O., Nóbrega, J. de A., Souza, G. \& Ana, N. ESPECIAÇÃO REDOX DE CROMO EM SOLO ACIDENTALMENTE CONTAMINADO COM SOLUÇÃO SULFOCRÔMICA. Quim. Nov. 31, 1450-1454 (2008).

19. Standard Methods for the Examination of Water and Wastewater Part 1000 Standard Methods for the Examination of Water and Wastewater. (1999).

20. Hu, J., Lo, I. M. C. \& Chen, G. H. Comparative study of various magnetic nanoparticles for $\mathrm{Cr}(\mathrm{VI})$ removal. Sep. Purif. Technol. 56, 249-256 (2007).

21. Chowdhury, S. R. \& Yanful, E. K. Arsenic and chromium removal by mixed magnetite-maghemite nanoparticles and the effect of phosphate on removal. J. Environ. Manage. 91, 2238-47 (2010).

22. Lei № 9.605, De 12 DE FEVEREIRO DE 1998. at <http://www.planalto.gov.br/ccivil_03/LEIS/L9605.htm>

23. Oliveira, A. H. A. \& Prado, A. G. S. Remoção de $\mathrm{Pb}(\mathrm{II})$ e $\mathrm{Cr}(\mathrm{VI})$ de efluentes industriais utilizando resíduos de Ipê (Tabebuia spp.), Maçaranduba (Manilkara spp.) e Pequiá (Caryocar spp.). 61 (2008).

24. Hu, J., Chen, G. \& Ã, I. M. C. Lo. Removal and recovery of $\mathrm{Cr}(\mathrm{VI})$ from wastewater by maghemite nanoparticles. Water Res. 39, 4528-4536 (2005).

25. Wolhfarth, E. P. Ferromagnetic Materials. North-holl. Publ. Co. (1982).

26. MEDEIROS, W. C. DE. UTILIZAÇÃO DE PARÂMETROS QUEChERS NA COMPARAÇÃO DE MÉTODOS DE DETERMINAÇÃO DA DENSIDADE SUPERFICIAL DE CARGA ESTRUTURAL DE NANOCOLOIDES MAGNÉTICOS. 65 (2014).

27. BioGeo Learning - Origem da multicelularidade. (2016). at $<$ http://biogeolearning.com/site/v1/biologia-11o-ano-indice/evolucaobiologica/origem-da-multicelularidade/>

28. Universidade de Bras ' Ilia Instituto de F' Isica Efeito da Varia , $\mathrm{C}^{\text { }}$ ao do Processo de $S$ ' Intese nas Propriedades Estruturais de Nanopart ' Iculas de Camila Messias Barbosa Santos. (2008).

29. R. Aquino, F.A. Tourinho, R. Itri, M.C.F.L. Lara, J. D.- \& Peyrot, J. No Title. Magn. \& Magn. Mater. 252, 23-25. 
30. Tourinho, F. A., Franck, R. \& Massart, R. No Title. J. Mater. Sci. 25, (1990).

31. Pereira, J. A. M. Espectros de Raios-X. Inst. Física - USP at $<$ <ttp://www.geocities.ws/raioxusp/aula2/aula2.html>

32. Melo, N. F. S. de et al. Desenvolvimento e caracterização de nanocápsulas de poli (L-lactídeo) contendo benzocaína. Quím. Nov. vol.33, (2010).

33. Lu, H.M., Zheng, W.T., Jiang, Q., J. No Title. Phys. D 40, 320-325 (2007).

34. Mior, R. UNIVERSIDADE FEDERAL DE SANTA CATARINA PARA PRÉCONCENTRAÇÃO DE CROMO USANDO MICROEXTRAÇÃO LÍQUIDOLÍQUIDO E DETERMINAÇÃO POR ESPECTROMETRIA DE ABSORÇÃO ATÔMICA EM CHAMA Relatório apresentado ao Departamento de Química da Universidade Federal de Santa Cat. (2009).

35. Miranda, W. D. \& Miyashiro, G. PROCESSOS DE VALIDAÇÃO E AVALIAÇÃO DOS NÍVEIS DE Cr E Cd EM ÁGUA PARA DIÁLISE DE CLÍNICAS NO ESTADO DE GOIÁS. GI. Sci. Technol. v. 01, n. , p.34 - 40 (2008).

36. Wang, P. \& Lo, I. M. C. Synthesis of mesoporous magnetic $y-\mathrm{Fe} 2 \mathrm{O} 3$ and its application to $\mathrm{Cr}(\mathrm{VI})$ removal from contaminated water. Water Res. 43, 3727-3734 (2009).

37. Dawodu, F. A., Akpomie, G. K. \& Ogbu, I. C. Isotherm Modeling on the Equilibrium Sorption of Cadmium ( II ) from Solution by Agbani Clay. Int. J. Multidiscip. Sci. Eng. 3, 9-14 (2012).

38. Azizian, S. No Title. J. Colloid Interface Sci. 276, 47-52 (2004).

39. Rafatullah, M., Sulaiman, O., Hashim, R. \& Ahmad, a. Adsorption of copper (II), chromium (III), nickel (II) and lead (II) ions from aqueous solutions by meranti sawdust. J. Hazard. Mater. 170, 969-977 (2009).

40. Arivoli, S., Hema, M., Karuppaiah, M. \& Saravanan, S. Adsorption of Chromium Ion by Acid Activated Low Cost Carbon-Kinetic, Mechanistic, Thermodynamic and Equilibrium Studies. E-Journal Chem. 5, 820-831 (2008).

41. Bhattacharya, a. K., Mandal, S. N. \& Das, S. K. Adsorption of Zn(II) from aqueous solution by using different adsorbents. Chem. Eng. J. 123, 43- 
51 (2006).

42. Pandey, P., Sambi, S., Sharma, S. \& Singh, S. Batch Adsorption Studies for the Removal of Cu (II) lons by ZeoliteNaX from Aqueous Stream. Proc. World Congr. Eng. Comput. Sci. 1 (2009).

43. Malik, P. K. Dye removal from wastewater using activated carbon developed from sawdust: adsorption equilibrium and kinetics. J. Hazard. Mater. 113, 81-88 (2004).

44. Nemr, A. El, Abdelwahab, O., El-Sikaily, A. \& Khaled, A. Removal of direct blue-86 from aqueous solution by new activated carbon developed from orange peel. J. Hazard. Mater. 161, 102-110 (2009).

45. Karagöz, S., Tay, T., Ucar, S. \& Erdem, M. Activated carbons from waste biomass by sulfuric acid activation and their use on methylene blue adsorption. Bioresour. Technol. 99, 6214-6222 (2008).

46. Pandey, P. K., Sharma, S. K. \& Sambi, S. S. Kinetics and equilibrium study of chromium adsorption on zeoliteNaX. Int. J. Environ. Sci. Technol. 7, 395-404 (2010).

47. Saroj, K. et al. Kinetic, Thermodynamic and Equilibrium Study on Removal of Lead ( II ) from Aqueous Solution Using Fly Ash. Internatinal Res. J. Environ. Sci. 3, 83-92 (2014).

48. Kundu, S. \& Gupta, A. K. Investigations on the adsorption efficiency of iron oxide coated cement (IOCC) towards As(V)--kinetics, equilibrium and thermodynamic studies. Colloids Surfaces A Physicochem. Eng. Asp. 273, 121-128 (2006).

49. Ho, Y. S. Review of second-order models for adsorption systems. J. Hazard. Mater. 136, 681-689 (2006).

50. Pang, Y. et al. Preparation and application of stability enhanced magnetic nanoparticles for rapid removal of $\mathrm{Cr}$ ( VI ). Chem. Eng. J. 175, 222-227 (2011).

51. Anirudhan, T. S. \& Radhakrishnan, P. G. Thermodynamics and kinetics of adsorption of $\mathrm{Cu}(\mathrm{II})$ from aqueous solutions onto a new cation exchanger derived from tamarind fruit shell. J. Chem. Thermodyn. 40, 702-709 (2008).

52. Samarghandi, M. R., Hadi, M., Moayedi, S. \& Askari, F. B. TwoParameter Isotherms of Methyl Orange Sorption By Pinecone Derived 
Activated Carbon. Environ. Heal. 6, 285-294 (2009).

53. Dotto, G., Vieira, M., Gonçalves, J. \& Pinto, L. Artigo. Quim. Nov. 34, 1193-1199 (2011).

54. Note, T. Technical Note 26 Determination of $\mathrm{Cr}(\mathrm{VI})$ in Water , Waste Water , and Solid Waste Extracts. Dionex

55. Khan, S. a., Riaz-ur-Rehman \& Khan, M. a. Adsorption of chromium (III), chromium (VI) and silver (I) on bentonite. Waste Manag. 15, 271-282 (1995).

56. Campos, A. F. C., Aquino, R., Tourinho, F. A., Paula, F. L. O. \& Depeyrot, J. A. F. C. Campos, R. Aquino, F. A. Tourinho, F. L. O. Paula, J. Depeyrot. Eur. Phys. J. E 36, 42 (2013).

57. Chen, B. et al. No Title. Ind. Eng. Chem. Res. 51, 12933 - 129393 (2012).

58. Khosa, M. a. \& Ullah, A. In-situ modification, regeneration, and application of keratin biopolymer for arsenic removal. J. Hazard. Mater. 278, 360-371 (2014).

59. Srivastava, V. C., Mall, I. D. \& Mishra, I. M. No Title. Chem. Eng. J. 132, 267 (2007). 